\title{
Computerizing Industries and Routinizing Jobs: Explaining Trends in Aggregate Productivity*
}

\author{
Sangmin Aum ${ }^{\dagger} \quad$ Sang Yoon (Tim) Lee Yongseok Shin $^{\S}$
}

April 9, 2018

\begin{abstract}
Complementarity across occupations and industries implies that the relative size of those with high productivity growth shrinks, reducing their contributions toward aggregate productivity growth and thereby resulting in its slowdown. This force, especially the shrinkage of occupations with above-average productivity growth through "routinization," was present since the 1980s. Through the end of the 1990s, it was countervailed by the extraordinary productivity growth in the computer industry, of which output became an increasingly more important input in all industries ("computerization"). It was only when the computer industry's productivity growth slowed that the negative effect of routinization on aggregate productivity became apparent.
\end{abstract}

Keywords: Aggregate productivity slowdown, routinization, computerization, sectorspecific and task-specific productivity

JEL Classification: E22, O40, O47

${ }^{*}$ We thank our discussant, Matthias Kehrig, for exceptionally detailed and constructive suggestions, and other conference participants for many useful comments. We also benefited from extended conversations about this paper with Christian Siegel, Henry Siu, and Sevin Yeltekin. The usual disclaimer applies.

$\dagger$ Washington University in St. Louis: s.aum@wustl .edu.

$\ddagger$ Toulouse School of Economics and CEPR: sylee.tim@tse-fr.eu.

$\S$ Corresponding author, Washington University in St. Louis, Federal Reserve Bank of St. Louis and NBER: yshin@wustl.edu. One Brookings Dr, St. Louis, Missouri, USA, +1-314-935-7138 


\section{Introduction}

Amid the sluggish recovery following the Great Recession, much attention has been given to the slowdown in productivity growth in the United States economy (sometimes referred to as "secular stagnation"). We dissect this trend in aggregate productivity by developing a model in which technological progress is both sector- and occupationspecific, ${ }^{1}$ to better understand which sectors and occupations contribute most to trends in aggregate productivity. ${ }^{2}$ In particular, we pay special attention to the computer sector (hardware and software), which enjoyed an impressive rise in productivity even as the rest of the economy lagged behind. Computers have become an important factor of production for all other sectors, especially since the 1990s (which we call "computerization"), so we separate them from other machinery equipment as a distinct type of capital. Using the model, we quantify the importance of the computer sector and compare it against "routinization" (i.e., faster technological progress specific to occupations that involve routine or repetitive tasks) in explaining trends in aggregate productivity.

We find that a downward trend in aggregate productivity growth was already present since the 1970s, but that this was more than compensated for by the extraordinary productivity growth of the computer sector in the 1980s and 1990s. It was only when the computer sector's productivity growth came down to normal levels in the 2000s that the deceleration in aggregate productivity became abruptly apparent. This generated the illusion that the aggregate productivity slowdown has its roots in the 2000s, even though the slowdown had already been underway in the preceding decades.

In our analysis, the driving force of the aggregate productivity slowdown is complementarity across occupations and across industries in production: Those occupations and industries with above-average productivity growth shrink in terms of value-added and employment shares, so they contribute less toward aggregate productivity growth when their productivity continues to grow fast. This is related to "Baumol's disease," i.e., that aggregate productivity growth can slow down because sectors with high productivity growth may decline in importance (e.g., manufacturing). However, our results show that it is the shrinkage of occupations with fast occupation-specific productiv-

\footnotetext{
${ }^{1}$ Throughout the text, we will use "sector" and "industry" interchangeably, as well as "occupations" and "jobs."

${ }^{2}$ Our model will admit an aggregate productivity that is distinct from conventional measures of total factor productivity (TFP), which assumes a homogeneous of degree one (HD1) production function in the two factors of capital and labor. When distinction is necessary, we will refer to our version with three factors (capital, labor and computers) simply as "productivity," and the two-factor residual as "TFP."
} 
ity growth, not sectors, that accounts for most of the downward trend in aggregate productivity growth.

Another novel element of our analysis is the computer sector. When sectors are complementary to one another, the extraordinarily high productivity growth of the computer sector should reduce its relative importance, and hence its contribution to aggregate productivity growth over time (Baumol's disease). However, because we model the computer sector's output as a distinct type of capital used in the production of all sectors (including itself), its productivity growth and the accompanying fall in its price boost the demand for computers from all sectors. Consequently, the computer sector's contribution to aggregate productivity remained important for a prolonged period of time, more than offsetting the negative effect of routinization on aggregate productivity growth for over two decades. We also show that computerization accounts for most of the decline in the labor income share since the 1980s.

In our model, individuals inelastically supply labor to differentiated jobs. Each sector uses all these jobs, but with different intensities. Sectors are complementary across one another for the production of the final good. Within each sector, jobs are also complementary to one another, and labor is combined with capital for sectoral production. Most important, we divide capital into computer capital (including software) and the rest (i.e., all capital not produced from the computer sector), and assume that the substitutability between labor and computer capital may differ across sectors. We model computer and software as capital used by all other sectors rather than an intermediate input, because the computer share of all investment is substantially larger than its share of all intermediates (14 vs. 2 percent, averaged between 1980 and 2010).

It should be noted that computerization and routinization are empirically distinct phenomena. Computer and software usage increased the most for high-skill or cognitive occupations, not middle-skill or routine occupations (Aum, 2017), justifying our choice to model productivity growth in both dimensions (sector- and occupationspecific). We then estimate the degree of complementarity across sectors, and calibrate the growth rates of the sector- and occupation-specific productivities, substitutability/complementarity across jobs, and substitutability between computer capital and labor, using detailed data on employment shares and computer capital by industry and by occupation. Our estimation and calibration verify that as long as productivity growth rates are positive, (i) sectors are complementary to one another for final good production; ${ }^{3}$ (ii) jobs are complementary to one another within sectors; and most important, (iii) computer capital is in fact substitutable with labor in all sectors.

\footnotetext{
${ }^{3}$ Or consumption, which we do not model.
} 
Given the structure of our model and the parameters we estimate/calibrate, and assuming that sector- and occupation-specific productivities grow at constant but different rates, we find that aggregate productivity growth declines over time due to the two types of complementarity (across jobs within sectors, and across sectors in final good production). Jobs and sectors with relatively higher productivity growth shrink in terms of employment and value-added. Then low-growth jobs and sectors gain more weight when computing aggregate productivity growth, resulting in its slowdown. As productivity growth slows down, output growth slows down even more.

The mechanics of our model are consistent with our empirical findings: Since the 1980s, sectors that rely heavily on routine jobs experienced the highest growth in their TFP's, as measured by conventional growth accounting. ${ }^{4}$ These occupations, and the sectors that rely relatively more on them, also saw their employment shares fall.

Next, we find that the fall in aggregate productivity growth in the longer run is more due to the differential growth across occupations (i.e., routinization) rather than the differential growth across sectors. In fact, if all occupation-specific productivities had grown at a common rate from 1980, holding all else equal, aggregate productivity growth rates would have stayed nearly constant through 2010. This contrasts with Baumol's disease, which emphasizes the differential sector-specific productivity growths, especially the slow productivity growth of the service sector.

The natural question is then why the downward trend in aggregate productivity growth did not manifest itself until the 2000s. In our model, the slowdown in aggregate productivity growth can be temporarily arrested and even reversed if certain sectors or jobs experience faster-than-usual technological progress. We find that this is exactly what happened during the 1990s, when the computer sector recorded impressive productivity growth. Without the technological progress specific to the computer industry, aggregate productivity growth during the 1990s would have been 0.5 percent per year, instead of 0.8 percent. It is only after the subsequent slowdown in the computer sector's productivity growth in the 2000s that the longer-run downward trend in aggregate productivity growth became apparent. Our analysis confirms that if productivity growth in the computer sector had been completely absent, aggregate productivity growth would have declined monotonically since 1980. In fact, although our focus is on the slowdown toward the end of the sample period in Figure 1, a slowdown is also apparent in the 1970 s to early 1980 s.

\footnotetext{
${ }^{4}$ That is, assuming an HD1 production function with two factors, capital and labor. By "measured," we mean productivity or TFP obtained directly from the data by growth accounting, as opposed to being computed from our model.
} 


\section{[ INSERT FIGURE 1 HERE ]}

In the data, sectors with higher measured TFP growth saw their employment shares decline, except for the computer sector. The same happens in our model because all sectors use computer capital in production. Then, as the computer sector's productivity growth reduces the price of computer capital, all sectors use more computers, which contributes to output growth in addition to the computer sector's direct contribution to aggregate productivity growth. ${ }^{5}$ Indeed, if there had been no productivity growth in the computer sector and hence no computerization, output per worker growth would have been 1.5 percent per year during the 1990s, rather than the 3.5 percent observed in the data. In other words, the sluggish growth of aggregate productivity and output in the 2000s was not abnormal. It was the faster-than-trend growth during the 1990s driven by the outburst of the computer sector's productivity that was extraordinary.

Treating computer capital as a separate production factor as we do also has implications for the measurement of aggregate productivity. We find that conventional TFP accounting with only two factor inputs, with all types of capital being summed up into a single category, overstates aggregate productivity growth by 0.4 percentage points per year when averaged between 1980 and 2010. That is, ignoring different types of capital, which differ in their rental and depreciation rates, can bias productivity measurements upward.

Lastly, we relate computerization to the decline in the labor income share. In our model, the labor share decline is caused by the substitutability between labor and computer capital, as the computer sector becomes more productive. We find that computerization during the 1990s accounts for most of the decline in the labor share between 1980 and 2010 (4 out of 5 percentage points), even the model does not target the labor share at all. This implies that computer capital alone is more important than all other machinery and equipment in explaining the decline in the labor share.

Related literature In our model, employment shifts across sectors - or "structural change" - occur due to differential sector- and occupation-specific productivity growth as in Lee and Shin (2017). Most studies in the structural change literature that consider sector-specific productivity growth, e.g., Ngai and Pissarides (2007), have paid little attention to its implications for changes in aggregate productivity. In fact, most were interested in obtaining balanced growth. However, since as far back as Baumol (1967),

\footnotetext{
${ }^{5}$ As discussed earlier, this model element is also important for understanding why the direct contribution of the computer sector to aggregate productivity growth did not dwindle in importance despite the complementarity across sectors. The computer sector's production share has been stable over time: 3.1 percent in the $1980 \mathrm{~s}, 3.4$ percent in the $1990 \mathrm{~s}, 3.9$ percent in the $2000 \mathrm{~s}$, and 3.4 percent in the $2010 \mathrm{~s}$.
} 
it was well known that complementarity between industries can lead to an increase in the employment share of the low productivity growth sector, consequently leading to a slowdown in aggregate productivity. A recent study by Duernecker, Herrendorf, and Valentinyi (2017) is a notable exception. They explicitly consider Baumol's disease in a multi-sector model, and evaluate whether structural change is quantitatively important for explaining the aggregate productivity slowdown. In our analysis, we model differential progress across occupation-specific technologies in addition to heterogeneous sector-specific productivity growth, and find that it was the dispersion of occupation-specific productivities that was more important for the aggregate productivity slowdown in the United States. ${ }^{6}$

Our work also relates to studies on the importance of information technology (IT) in explaining the evolution of productivity (e.g., Byrne, Fernald, and Reinsdorf, 2016; Syverson, 2017). In particular, Acemoglu, Autor, Dorn, Hanson, and Price (2014) investigate the relationship between productivity growth and IT capital intensity by industry, and conclude that IT usage has little impact on productivity. While we emphasize the role of computerization, our analysis is consistent with theirs. Computerization is important for shaping aggregate productivity growth in our analysis, but there is no direct effect of computerization on the productivity of other industries. Instead, computerization affects industry level output and value-added through an increase in the use of computer capital.

In many empirical analyses related to routinization, the price of information and communication technology (ICT) capital is often used as a proxy for routine-biased technological change (e.g., Goos, Manning, and Salomons, 2014; Cortes, Jaimovich, and Siu, 2017). However, when we break down computer usage by occupation, we find that computerization and routinization are two distinct phenomena, with different implications for the macroeconomy. Related, Aum (2017) analyzes increasing investment in software in a model that also features routinization. While Aum (2017) focuses on its impact on changes in occupational employment, we focus on its implications for aggregate productivity.

Finally, Karabarbounis and Neiman (2014) suggest that the decline in the labor income share could be due to a decline in the price of capital. Since the decline in the price of capital is mostly driven by the price of computer-related equipment, and it mirrors the productivity increase in the computer industry, our analysis concurs with their explanation of the declining labor share. Furthermore, our results show

\footnotetext{
${ }^{6}$ Aum, Lee, and Shin (2017) document occupation-specific and sector-specific shocks at a higher frequency - during and after the Great Recession.
} 
that a specific component of capital - computer hardware and software - can be more important than all other types of capital. This is in line with Koh, Santaeullia-Llopis, and Zheng (2016), who emphasize the importance of "intellectual property products" capital (including software) for the decline of the labor share.

\section{Empirical Evidence}

We begin by establishing that routinization and computerization are two distinct phenomena. For the empirical analysis, occupational data is from the decennial censuses and industrial data from the BEA industry accounts. We consider industries at the 2-digit level, resulting in 60 industries. In particular, we label industry 334 (computers and electronic products) the "hardware" industry and 511 (publishing industries including software) the "software" industry. The combination of both is the "computer sector."

\section{[ INSERT FIGURE 2 HERE ]}

In Figure 2(a), the horizontal axis is occupational employment shares (percentile), in ascending order of each occupation's 1980 average wage. ${ }^{7}$ The figure shows that the routine-task intensity (RTI) of occupations (Autor and Dorn, 2013) is high for middlewage occupations, as is well known in the routinization/polarization literature, but that high-wage occupations tend to use computers more. ${ }^{8}$ So at the occupational level, an increase in the use of computers (i.e., computerization) should be distinguished from routinization, which is typically understood as faster productivity growth among middle-wage or routine-intense tasks.

Computerization in our model is a consequence of the fast productivity growth of the computer industry. We first employ conventional accounting to measure each industry's TFP growth: the growth rate of real value-added net of the growth of capital

\footnotetext{
${ }^{7}$ The ordering of occupational mean wages barely changes from 1980 to 2010.

${ }^{8}$ Computer usage is approximated from 2010 NIPA Tables 5.5.5 (Private Fixed Investment in Equipment by Type), 5.6.5 (Private Fixed Investment in Intellectual Properties by Type), and the O*NET Tools and Technology database as follows. In NIPA Table 5.5.5, we assume that "computers and peripheral equipment" are produced by industry 334, and in Table 5.6.5, that "software" are produced by industry 511. O*NET lists all the tools and technology that are used for each occupation. O*NET occupation codes can be easily mapped to the census, and tools and technology are coded using the UNSPSC commodity system. We assume that 4321xxxx corresponds to "hardware," which includes all computers and peripheral equipment, and that 4323xxxx corresponds to "software." Then we count the number of distinct commodities needed in each occupation, multiply it by the employment share of that occupation, and assume that hardware and software investment is allocated across occupations proportionately to this number. Finally, we standardize this measure of computer investment by occupation to have a mean of zero and standard deviation of 1 . While this may be a crude measure for computer usage, it is highly correlated with data from the CPS, which reports computer use intensity by occupation. See Appendix A of Aum (2017) for more details.
} 
and labor inputs, weighted by the income share of each factor. Specifically, industry $i$ 's measured TFP growth between time $s$ and $t$ is

$$
\log \frac{T F P_{i t}}{T F P_{i s}}=\log \frac{Y_{i t}}{Y_{i s}}-\frac{\alpha_{i s}+\alpha_{i t}}{2} \cdot \log \frac{L_{i t}}{L_{i s}}-\frac{2-\alpha_{i s}-\alpha_{i t}}{2} \cdot \log \frac{K_{i t}}{K_{i s}},
$$

where $Y$ is real value-added, $L$ is employment, $K$ is the net real stock of non-residential fixed capital, and $\alpha$ is the labor share (compensation of employees divided by valueadded).$^{9}$

Figure 2(b) depicts the log-TFP of computer-related industries (BEA industry code 334 for hardware and 511 for software) and the average of the log-TFP of all industries excluding agriculture and government (weighted according to the Törnqvist index). The TFP of hardware shows an average annual growth rate of 16 percent, far higher than the average across all industries. Software also features higher TFP growth compared to the average. The TFP of the "computer industry" - the value- added weighted average of hardware and software - shows that the hardware industry mostly determines the TFP of the computer industry. Note that the exceptionally fast growth of the computer industry's TFP slowed down since around the early 2000s.

\section{[ INSERT FIGURE 3 HERE ]}

Reflecting the fast growth of the computer industry's measured TFP, the use of computer and software also rose substantially until the late 1990s. Figure 3(a) shows the computer and software share of total intermediates over time. Figure 3(b) plots the share of computers and software in total non-residential investment. In both figures, it is clear that there was a steep rise in the importance of computers in the 1980s to 1990s, which stagnated starting in the 2000s. ${ }^{10}$

\section{[ INSERT FIGURE 4 HERE ]}

We now turn to disaggregated evidence at the industry level, which will support our hypotheses of heterogeneous growth rates and complementarity across jobs and industries. Because job or occupation-level productivity is not directly measurable, we first establish two new empirical patterns, utilizing the fact that industries differ in the composition of their workers' occupations. Figure 4(a) shows that the routine job share of an industry is positively correlated with its measured TFP growth (log difference) between 1980 and 2010 (consistent with routinization), where routine jobs are defined as occupations that are above the 66 percentile in terms of the RTI index following

\footnotetext{
${ }^{9}$ Later when we separately consider computer capital, TFP computed here would be a misspecification.

${ }^{10}$ The data behind Figures 3(a) and (b) come from BEA's Input-Output Tables and Fixed Assets Tables, respectively.
} 
Autor and Dorn (2013). Figure 4(b) shows that TFP growth and employment growth are negatively correlated across industries, consistent with complementarity across jobs and/or industries. ${ }^{11}$

However, note that the computer industry is a conspicuous outlier. In Figure 4(a), despite having a routine job share around the median, not only is the computer industry's TFP growth 10 times larger than other industries at similar levels of routineness, it is in fact 2 to 4 times larger than the next two industries with the highest levels of TFP growth overall. Despite this, as shown in Figure 4(b), its employment barely fell. With complementarity across industries, a high productivity growth sector should lose value-added and employment shares. A possible explanation is that other industries depend heavily on the computer industry, so that even as its productivity grows the size of this sector would not shrink as long as other industries rely on it more. If so, those industries with faster growth in computer capital should grow faster than those that use computers less intensively in terms of output: since computer capital is a factor in production, it would not necessarily increase productivity. Figure 5 confirms the positive relationship between the growth of computer capital (total investment into hardware and software from 1980-2010) for an industry and its value-added growth between 1980 and 2010 .

\section{[ INSERT FIGURE 5 HERE ]}

\section{Model}

The model for our quantitative analysis builds on those in Goos et al. (2014) and Lee and Shin (2017), both of which simultaneously analyze an economy's occupational and industrial structure. In particular, the latter explicitly models how workers of heterogeneous skill sort into different occupations, and also industries that differ in the intensity with which they combine workers of different occupations for production. Here we ignore selection on skill, but instead expand previous models by letting all industries use output from the computer sector as a capital good in production, an important channel through which the productivity gains of the computer industry affect aggregate production.

\footnotetext{
${ }^{11}$ Employment in this figure is full-time plus part-time workers (FTPT). Full-time equivalent (FTE) employment shows similar patterns, but is only available by industry from 1997 onward. For this period, there are level differences between the two measures, but dynamic patterns are similar for both.
} 
Environment A representative household maximizes its discounted sum of utility

$$
\sum_{t=0}^{\infty} \beta^{t} u\left(C_{t}\right)
$$

subject to the sequence of budget constraints,

$$
C_{t}+I_{t}+p_{I, t} F_{t} \leq Y_{t},
$$

where $I$ is investment in traditional capital (machinery and equipment excluding computer hardware and software), $F$ investment in computer capital, and $p_{I}$ the price of computers. The final good is the numeraire, which can be used for consumption and traditional capital investment. The law of motion for each type of capital satisfies

$$
K_{t+1}=I_{t}+\left(1-\delta_{K}\right) K_{t}, \quad S_{t+1}=F_{t}+\left(1-\delta_{S}\right) S_{t},
$$

where $(K, S)$ are traditional and computer capital, respectively, and $\left(\delta_{K}, \delta_{S}\right)$ their depreciation rates. In what follows, we drop the time subscript unless necessary, and simply denote next period variables with a prime.

Within the representative household is a unit mass of identical individuals who supply labor inelastically to one of $J$ occupations, indexed by $j \in\{1, \ldots, J\}$. The final good is produced by combining products from $I$ sectors, which we index by $i \in\{1, \ldots, I\}$. To be specific, final good production combines industrial output using a CES aggregator with the elasticity of substitution $\epsilon$ :

$$
Y=\left[\sum_{i=1}^{I} \gamma_{i}^{\frac{1}{\epsilon}} Y_{i}^{\frac{\epsilon-1}{\epsilon}}\right]^{\frac{\epsilon}{\epsilon-1}}
$$

In each sector, a representative firm organizes the $J$ occupations to produce sectoral output $Y_{i}$ according to

$$
Y_{i}=A_{i} K_{i}^{\alpha_{i}} Z_{i}^{1-\alpha_{i}}
$$

where $A_{i}$ is industry $i$ 's exogenous sector-specific productivity and $Z_{i}$ a computer-labor composite that combines computer capital $S_{i}$ with an occupation composite $X_{i}$ :

$$
Z_{i}=\left[\omega_{i}^{\frac{1}{\rho_{i}}} S_{i}^{\frac{\rho_{i}-1}{\rho_{i}}}+\left(1-\omega_{i}\right)^{\frac{1}{\rho_{i}}} X_{i}^{\frac{\rho_{i}-1}{\rho_{i}}}\right]^{\frac{\rho_{i}}{\rho_{i}-1}}, \quad X_{i}=\left[\sum_{j=1}^{J} \nu_{i j}^{\frac{1}{\sigma}}\left(M_{j} L_{i j}\right)^{\frac{\sigma-1}{\sigma}}\right]^{\frac{\sigma}{\sigma-1}} .
$$

Each $L_{i j}$ is the number of occupation $j$ labor (i.e., workers) used in sector $i$, and $M_{j}$ is the exogenous occupation-specific productivity of job $j$ that differs across occupations but not sectors. The parameters $\omega_{i}$ and $\nu_{i j}$ are CES weights that differ by sector, as well 
as $\rho_{i}$, the elasticity of substitution between computers and labor in sector $i$. However, we assume that the elasticity of substitution across occupations, $\sigma$, is identical across sectors. There are several reasons we let the $\rho$ 's vary across sectors but not $\sigma$, which we discuss in Section 4.2.

Since each industry uses all types of occupations but with different intensities $\nu_{i j}$, changes in $M_{j}$ would have differential effects on the occupation composite $X_{i}$, and thus on $Z_{i}$, the computer-labor composite. Ultimately, it will manifest itself as differential effects on sectoral productivity and output. In contrast, changes in $A_{i}$ affects sectoral productivity and output directly.

Computer capital $S_{i}$ is also used in all sectors, and without loss of generality we will assume that the computer industry is industry $i=I$. So the total amount of computer capital in the economy is $S=\sum_{i=1}^{I} S_{i}$ and $F$ is the total amount of newly produced computers. While the model assumes that computer capital is required for production in all industries, there is no other input-output linkage among the rest. Each industry rents traditional capital and computer capital at rates $R_{K}$ and $R_{S}$.

Equilibrium The final good firm takes prices $p_{i}$ as given and solves

$$
\max \left\{Y-\sum_{i=1}^{I} p_{i} Y_{i}\right\} .
$$

Each sector $i$ firm takes all prices as given and chooses capital, computer capital and labor to solve

$$
\max \left\{p_{i} Y_{i}-R_{K} K_{i}-R_{S} S_{i}-w \sum_{j=1}^{J} L_{i j}\right\},
$$

where $p_{i}$ is the price of the sector $i$ good, $R_{K}$ the rental rate of traditional capital, $R_{S}$ the rental rate of computer capital, and $w$ the wage rate - which is equal across jobs since individuals do not differ in skill. In a competitive equilibrium, the followings are satisfied.

First, final good producers choose $Y_{i}$ to maximize profits (2), so

$$
\gamma_{i} Y / Y_{i}=p_{i}^{\epsilon} \quad \text { for } i \in\{1, \ldots, I\}
$$

Since we normalized the final good price to 1 ,

$$
\sum_{i=1}^{I} \gamma_{i} p_{i}^{1-\epsilon}=1^{\frac{1}{1-\epsilon}}=1
$$

is the ideal price index. 
Second, all sector $i$ firms maximize profits (3). The first-order necessary conditions are

$$
\begin{aligned}
R_{K} & =\alpha_{i} p_{i} Y_{i} / K_{i} \\
R_{S} & =\left(1-\alpha_{i}\right) \cdot\left(p_{i} Y_{i} / Z_{i}\right) \cdot\left(\omega_{i} Z_{i} / S_{i}\right)^{\frac{1}{\rho_{i}}} \\
w & =\left(1-\alpha_{i}\right) \cdot\left(p_{i} Y_{i} / Z_{i}\right) \cdot\left[\left(1-\omega_{i}\right) Z_{i} / X_{i}\right]^{\frac{1}{\rho_{i}}} \cdot\left[\nu_{i j} \tilde{M}_{j} X_{i} / L_{i j}\right]^{\frac{1}{\sigma}}
\end{aligned}
$$

where $\tilde{M}:=M^{\sigma-1}$.

Third, capital, computer and labor markets clear:

$$
K=\sum_{i=1}^{I} K_{i}, \quad S=\sum_{i=1}^{I} S_{i}, \quad L=\sum_{i=1}^{I} L_{i}=\sum_{i=1}^{I}\left[\sum_{j=1}^{J} L_{i j}\right]
$$

where $L_{i}:=\sum_{j} L_{i j}$ is the total amount of labor used in sector $i$.

Finally, the rental rates satisfy

$$
\frac{u^{\prime}(C)}{\beta u^{\prime}\left(C^{\prime}\right)}=1+r=R_{K}^{\prime}+\left(1-\delta_{K}\right)=\left[R_{S}^{\prime}+\left(1-\delta_{S}\right) p_{I}^{\prime}\right] / p_{I},
$$

and the transversality conditions hold.

$$
\lim _{t \rightarrow \infty} \beta^{t} u^{\prime}\left(C_{t}\right) K_{t}=0, \quad \lim _{t \rightarrow \infty} \beta^{t} u^{\prime}\left(C_{t}\right) S_{t}=0
$$

Equilibrium Characterization From (4) and (5a), we find that

$$
\alpha_{i} p_{i} y_{i} / \alpha_{I} p_{I} y_{I}=k_{i} / k_{I}=\left(\alpha_{i} / \alpha_{I}\right)\left(\gamma_{i} / \gamma_{I}\right)^{\frac{1}{\epsilon}} \cdot\left(y_{i} / y_{I}\right)^{\frac{\epsilon-1}{\epsilon}} \cdot\left(L_{i} / L_{I}\right)^{-\frac{1}{\epsilon}}
$$

where $y_{i}:=Y_{i} / L_{i}$ is output per worker and $k_{i}:=K_{i} / L_{i}$ is capital per worker in sector $i$. So using (1), we can write

$$
\frac{A_{i}}{A_{I}}=\left(\frac{\alpha_{I}}{\alpha_{i}}\right)^{\frac{\epsilon}{\epsilon-1}} \cdot \frac{k_{i}^{\frac{\epsilon}{\epsilon-1}-\alpha_{i}}}{k_{I}^{\frac{\epsilon}{\epsilon-1}-\alpha_{I}}} \cdot \frac{z_{I}^{1-\alpha_{I}}}{z_{i}^{1-\alpha_{i}}} \cdot\left(\frac{\gamma_{I} L_{i}}{\gamma_{i} L_{I}}\right)^{\frac{1}{\epsilon-1}}
$$

where $\left(z_{i}, s_{i}\right)$ is the labor productivity and computer per worker in sector $i$. From (5c), holding $i$ fixed we obtain $L_{i j} / L_{i 1}=\nu_{i j} \tilde{M}_{j} / \nu_{i 1} \tilde{M}_{1}$ for all $j$, so

$$
L_{i j}=\left(\tilde{V}_{i}^{1-\sigma} \cdot \nu_{i j} \tilde{M}_{j}\right) \cdot L_{i} \text { and } X_{i}=\tilde{V}_{i} L_{i}, \quad \text { where } \tilde{V}_{i}:=\left(\sum_{j=1}^{J} \nu_{i j} \tilde{M}_{j}\right)^{\frac{1}{\sigma-1}}
$$

Then the equilibrium allocations of $\left(L_{i j}, Z_{i}\right)$ can be expressed as

$$
L_{i j} / L_{i}=\nu_{i j} \tilde{M}_{j} \tilde{V}_{i}^{1-\sigma}, \quad \text { and }
$$




$$
Z_{i}=\left[\omega_{i}^{\frac{1}{\rho_{i}}} S_{i}^{\frac{\rho_{i}-1}{\rho_{i}}}+V_{i}^{\frac{1}{\rho_{i}}} L_{i}^{\frac{\rho_{i}-1}{\rho_{i}}}\right]^{\frac{\rho_{i}}{\rho_{i}-1}} \Rightarrow z_{i}:=Z_{i} / L_{i}=\left[\omega_{i}^{\frac{1}{\rho_{i}}} s_{i}^{\frac{\rho_{i}-1}{\rho_{i}}}+V_{i}^{\frac{1}{\rho_{i}}}\right]^{\frac{\rho_{i}}{\rho_{i}-1}}
$$

where $V_{i}:=\left(1-\omega_{i}\right) \tilde{V}_{i}^{\rho_{i}-1}$. Plugging these expressions into $(5 \mathrm{~b})$ and $(5 \mathrm{c})$ we obtain

$$
\begin{aligned}
R_{S} & =\left(1-\alpha_{i}\right) \cdot\left(p_{i} y_{i} / z_{i}\right) \cdot\left(\omega_{i} z_{i} / s_{i}\right)^{\frac{1}{\rho_{i}}} \\
w & =\left(1-\alpha_{i}\right) \cdot\left(p_{i} y_{i} / z_{i}\right) \cdot\left(V_{i} z_{i}\right)^{\frac{1}{\rho_{i}}}
\end{aligned}
$$

and taking the wage-computer rent ratio $\left(w / R_{S}\right)$ across all sectors, we can express all other sectors' computer capital per worker relative to the computer sector's:

$$
\left(V_{i} / \omega_{i}\right) \cdot s_{i}=\left[\left(V_{I} / \omega_{I}\right) \cdot s_{I}\right]^{\frac{\rho_{i}}{\rho_{I}}}
$$

and plugging this expression into the definition of $z_{i}$ in (11), we obtain

$$
z_{i}=V_{i}^{\frac{1}{\rho_{i}-1}}\left[1+\left(\omega_{i} / V_{i}\right)\left[\left(V_{I} / \omega_{I}\right) \cdot s_{I}\right]^{\frac{\rho_{i}-1}{\rho_{I}}}\right]^{\frac{\rho_{i}}{\rho_{i}-1}} .
$$

Thus, all $z_{i}$ 's can be obtained given $s_{I}$, the computer sector's computer capital per worker, and exogenous parameters. Similarly, taking the wage-capital rent ratio $\left(w / R_{K}\right)$ across all sectors using (5a) and (12b), we obtain

$$
\frac{\left(1-\alpha_{i}\right) \alpha_{I}}{\left(1-\alpha_{I}\right) \alpha_{i}} \cdot \frac{k_{i}}{k_{I}}=\left(z_{i}^{\frac{\rho_{i}-1}{\rho_{i}}} / z_{I}^{\frac{\rho_{I}-1}{\rho_{I}}}\right) /\left(V_{i}^{\frac{1}{\rho_{i}}} / V_{I}^{\frac{1}{\rho_{I}}}\right),
$$

and since all $z_{i}$ 's are functions of $s_{I}$, all $k_{i}$ 's can be obtained given $s_{I}$ and $k_{I}$ 's, the computer sector's traditional capital per worker. So the equilibrium allocation can be found from (8) subject to the market clearing conditions (6).

Discussion In our model, sector- and occupation-specific productivities are exogenous ( $A_{i}$ and $M_{j}$, respectively). In particular, sector-specific productivities $A_{i}$ are distinct from "sectoral productivity" which refers to the productivity of a sector in an accounting sense. And since the occupation-specific productivities affect sectoral productivity through $V_{i}:=\left(1-\omega_{i}\right)\left(\sum_{j} \nu_{i j} \tilde{M}_{j}\right)^{\frac{\rho_{i}-1}{\sigma-1}}$, sectoral productivity depends on $M_{j}$ 's as well as $A_{i}$. Specifically, sectoral productivity in our model is obtained by decomposing output into factors:

$$
\hat{y}_{i}=\underbrace{\left[\hat{A}_{i}+\left(1-\alpha_{i}\right) \frac{1}{\rho_{i}-1} \frac{V_{i}^{\frac{1}{\rho_{i}}}}{z_{i}^{\rho_{i}-1}} \hat{V}_{i}\right]}_{\text {Sectoral Productivity }}+\underbrace{\alpha_{i}}_{K \text { share }} \hat{k}_{i}+\underbrace{\left(1-\alpha_{i}\right) \frac{\omega_{i}^{\frac{1}{\rho_{i}}} \frac{s_{i}}{\rho_{i}-1}}{z_{i}^{\rho_{i}-1}}}_{S \text { share }} \hat{s}_{i},
$$


where $\hat{x}:=d \log x$.

The above is our definition of productivity in the subsequent quantitative analysis, which is distinct from traditional measures of TFP. ${ }^{12}$ A rise in $M_{j}$, the occupationspecific productivity of job $j$, raises sectoral productivity through changes in $V_{i}$. In this case, all sectoral productivities would move in the same direction (either up or down), but their growth rates will differ depending on the sector-specific parameters included in the expression for sectoral productivity in (16), as well as the endogenous response of $z_{i}$. And since the production technology is homogeneous of degree one (HD1), aggregate productivity is a sectoral output-weighted average of the sectoral productivities. Hence changes in the exogenous productivities $A_{i}$ or $M_{j}$ affect aggregate productivity both directly by changing all sector's sectoral productivities, but also indirectly by altering sectoral output shares.

Last but not least, changes in $A_{I}$, the computer industry's sector-specific productivity, has further repercussions on aggregate output. As other industries, changes in $A_{I}$ alter aggregate productivity both directly (by increasing the computer sector's sectoral productivity) and indirectly (by altering the output share of the computer industry). But in addition, it lowers the price of computers $\left(p_{I}\right)$ and consequently the rental rate of computer capital $\left(R_{S}\right)$, leading to a rise in the use of computers for industries whose elasticity of substitution between computers and labor $\left(\rho_{i}\right)$ is larger than one. Consequently, not only because it raises aggregate productivity, but also because it increases the use of computers in all sectors, a rise in $A_{I}$ contributes more to an increase in aggregate output than any other sector-specific productivity does.

\section{Quantitative Analysis}

For the quantitative analysis, we classify industries into ten groups as summarized in Table 1. We exclude the agricultural sector and government. In Table 2, we classify occupations into ten groups which broadly correspond to one-digit occupation groups in the census. We then fit the model exactly to the data for 1980, and let only the exogenous occupation- and sector-specific productivities $\left(M_{j}, A_{i}\right)$ grow at a constant rate. Thus, a major test of the model is how well it replicates the data in 2010, or equivalently, the growth of sectoral and aggregate variables from 1980 to 2010.

\section{[ INSERT TABLES 1 AND 2 HERE ]}

\footnotetext{
${ }^{12}$ The difference is that conventional TFP measurements separate only capital and labor, while we are taking out computers as a distinct type of capital with its own income share.
} 


\subsection{Calibration}

Aggregate production function The parameters of the final good production function are estimated outside of the model using real and nominal value-added data by industry. Specifically, we estimate the sectoral weights $\gamma_{i}$ and complementarity parameter $\epsilon$ from

$$
\log \left(p_{i} Y_{i} / p_{I} Y_{I}\right)=\frac{1}{\epsilon}\left(\gamma_{i} / \gamma_{I}\right)+\frac{\epsilon-1}{\epsilon} \log \left(Y_{i} / Y_{I}\right), \text { for } i=1, \cdots, I-1 .
$$

This system of equations is estimated by iterated feasible generalized nonlinear least squares method. To reflect constraints on the parameters $\left(\epsilon>0\right.$ and $\left.0<\gamma_{i}<1\right)$, we estimate the unconstrained coefficents $b$ and $c_{i}$ 's in

$$
\log \left(p_{i, t} Y_{i, t} / p_{I, t} Y_{I, t}\right)=\left(1+e^{b}\right) c_{i}+e^{b} \log \left(Y_{i, t} / Y_{I, t}\right)+\varepsilon_{i, t},
$$

where $\epsilon=1 /\left(1+e^{b}\right)$ and $\gamma_{i}=e^{c_{i}} /\left(1+\sum e^{c_{i}}\right)$.

Each sector $i$ in the model consists of several industries in the BEA Industry Accounts, to which we apply the Törnqvist index to obtain the price index of sector $i$. Real quantities $Y_{i}$ are similarly aggregated up from the detailed BEA data. The aggregate price index is normalized to 1 in 1963, the initial year in the data. The sample period for the estimation covers 1980 to 2010, which is our main interest. The point estimates for $\epsilon$ and $\gamma_{i}$ are presented in Table 3 .

\section{[ INSERT TABLE 3 HERE ]}

Parameters calibrated without simulation In the calibration, we fix the traditional capital share of only the computer industry $\left(\alpha_{I}\right)$ from the data. Though computing the total capital share is straightforward (i.e., 1 minus labor share), computing the traditional capital share according to our model is not. To obtain this number for the computer industry, we follow Koh et al. (2016), which we briefly describe below.

We begin by specifying an empirical no-arbitrage condition for rental prices. The return on both types of capital must be equal to the interest rate $1+r^{\prime}$, so

$$
\left[R_{K}^{\prime}+\left(1-\delta_{K}^{\prime}\right) p_{K}^{\prime}\right] / p_{K}=\left[R_{S}^{\prime}+\left(1-\delta_{S}^{\prime}\right) p_{I}^{\prime}\right] / p_{I}
$$

where $p_{K}$ is the price of traditional capital and $p_{I}$ the price of computers. Note that this is different from the model's no-arbitrage condition (7) in that we have included the price of capital, which in the model we had normalized to be equal to the price of the final consumption good. Next, since sectoral production is HD1 in all factor inputs (traditional and computer capital, and labor), for the computer industry we have

$$
1 \text { - labor share } I=\frac{R_{K} K_{I}}{p_{I} Y_{I}}+\frac{R_{S} S_{I}}{p_{I} Y_{I}} .
$$


We solve for $R_{K}$ and $R_{S}$ from these two equations assuming a steady state $\left(R_{K}^{\prime}=\right.$ $R_{K}, R_{S}^{\prime}=R_{S}$ and $p_{K}=p_{K}^{\prime}, p_{I}=p_{I}^{\prime}$ ), plugging in for all other variables using data on the quantities, prices and depreciation rates of each type of capital (from BEA FAT Nonresidential Estimates by Industry and Type); and the computer industry's real and nominal value-added, and its labor share (from BEA Industry Accounts). ${ }^{13}$ Once we know $R_{S}$, we can set $\alpha_{I}=R_{S} S_{I} / p_{I} Y_{I}$ since all other variables are recovered directly from the data. We rely only on data from 1980.

Although the above procedure can be used for all industries, in our calibration we only use it to compute the computer industry's traditional capital share. All other industries' traditional capital shares are calibrated directly from the model as explained below. Appendix Figure 17(a) compares the traditional capital shares obtained using the above procedure against those predicted by the calibration, which confirms that they are generally consistent.

Method of Moments The rest of parameters are recovered from simulating model moments to match corresponding data moments. To be precise, we plug the data for $L_{i j}$ (from the IPUMS Census), and $\left(k_{i}, s_{i}\right)$ (from the BEA FAT Nonresidential Estimates by Industry and Type) directly into the equilibrium equations, assuming a steady state in both 1980 and 2010, respectively. The detailed procedure is as follows.

1. Guess $\sigma$.

(a) Fix $\alpha_{I}$ as above, and guess $A_{I, 1980}$ and $\rho_{i}$ 's.

i. For 1980: obtain $\left(\nu_{i j}, \omega_{i}, \alpha_{i}, A_{i, 1980}\right)$ given guess.

- Normalize $M_{j}=1$ for all $j$. Then the industry-specific occupation weights $\nu_{i j}$ 's and $\tilde{V}_{i}$ are recovered from (9)-(10) using data on 1980 employment shares..

- From (12a) of industry $I$, and replacing for $y_{i}$ using (1) and $z_{i}$ using (11), $\omega_{I}$ must solve

$$
R_{S}=\left(1-\alpha_{I}\right) \cdot A_{I} k_{I}^{\alpha_{I}} \cdot\left[\omega_{I}^{\frac{1}{\rho_{I}}} s_{I}^{\frac{\rho_{I}-1}{\rho_{I}}}+\left(1-\omega_{I}\right)^{\frac{1}{\rho_{I}}} \tilde{V}_{I}^{\frac{\rho_{I}-1}{\rho_{I}}}\right]^{\frac{1-\rho_{I} \alpha_{I}}{\rho_{I}-1}} \cdot\left(\omega_{I} / s_{I}\right)^{\frac{1}{\rho_{I}}},
$$

given data on $k_{I}$ and $s_{I}$ in 1980. The solution $\omega_{I} \in(0,1)$ if $1<$ $\left(1-\alpha_{I}\right) A_{I}\left(k_{I} / s_{I}\right)^{\alpha_{I}}$.

- Given $\omega_{I}$, obtain all other $\omega_{i}$ 's from $(13)$ (since $\left.V:=\left(1-\omega_{i}\right) \tilde{V}_{i}^{\rho_{i}-1}\right)$.

\footnotetext{
13 We take the weighted average across industries 334 and 511 (software and hardware) to obtain this value for the computer industry, which in our quantitative model comprises both. For each industry, computer capital is the sum of the net stock of "computers and peripheral equipment" and "software."
} 
- For all $i \neq I$, compute $\alpha_{i}$ 's from (15) by replacing for $z_{i}$ using (14), and plugging in data on $\left(k_{i}, s_{i}\right)$.

- Exogenous sector-specific productivities $A_{i, 1980}$ 's are recovered from (8) and $A_{I, 1980}$.

ii. For 2010: obtain $M_{j, 2010}$ and updated guesses for the substitutability between computers and workers, $\rho_{i}^{\text {new }}$.

- Choose the $M_{j}$ 's that yields the best fit of (10) across all $i$ given 2010 employment shares:

$$
\frac{M_{j}}{M_{1}}=\left[\sum_{i}\left(L_{i} \cdot \frac{L_{i j}}{L_{i 1}} \cdot \frac{\nu_{i 1}}{\nu_{i j}}\right)\right] / \sum_{i} L_{i}
$$

Using this we can compute $\tilde{V}_{i}$ for 2010 using (9).

- From (15), we set $\rho_{I}^{\text {new }}$ to get the best fit of

$$
\rho_{I}^{\text {new }} \cdot I=\sum_{i}\left\{\frac{\log \left(\omega_{I} \tilde{V}_{I}\right)-\log \left(\left(1-\omega_{I}\right) s_{I}\right)}{\log \left[\left(1-\frac{\alpha_{I}\left(1-\alpha_{i}\right) k_{i}}{\alpha_{i}\left(1-\alpha_{I}\right) k_{I}}\right) \tilde{V}_{I}\right]-\log \left(\frac{s_{I} \alpha_{I}\left(1-\alpha_{i}\right) k_{i}}{\alpha_{i}\left(1-\alpha_{I}\right) k_{I}}-s_{i}\right)}\right\}
$$

given data on $\left(k_{i}, s_{i}\right)$ in 2010 .

Note that we need $s_{i} / s_{I}<\left(1-\alpha_{i}\right) \alpha_{I} k_{i} /\left(\alpha_{i}\left(1-\alpha_{I}\right) k_{I}\right)<1$ or $s_{i} / s_{I}>$ $\left(1-\alpha_{i}\right) \alpha_{I} k_{i} /\left(\alpha_{i}\left(1-\alpha_{I}\right) k_{I}\right)>1$ for $\rho_{I}^{\text {new }}$ to be a real number. We exclude those industries with $\left(k_{i}, s_{i}\right)$ for which this condition is not satisfied only when we compute $\rho_{I}^{\text {new }}$.

- Compute the implied $\rho_{i}^{\text {new }}$ 's that are consistent with the $2010 s_{i}$ 's, i.e.,

$$
\rho_{i}^{\text {new }}=\frac{\rho_{I}^{\text {new }} \log \left(\frac{1-\omega_{i}}{\omega_{i} s_{i} \tilde{V}_{i}}\right)}{\rho_{I}^{\text {new }} \log \left(\frac{\tilde{V}_{I}}{\tilde{V}_{i}}\right)+\log \left(\frac{1-\omega_{I}}{\omega_{I} s_{I} \tilde{V}_{I}}\right)}
$$

(b) Iterate over $\rho_{i}$ 's till $\rho_{i} \approx \rho_{i}^{\text {new }}$.

(c) Set $A_{I, 1980}$ so that $y_{I}$ equals the computer industry's real value-added per worker in the data. Iterate over $A_{I, 1980}$ till convergence.

2. Iterate over $\sigma$ to minimize $\sum_{j}\left|\ell_{j, 2010}^{d}-\ell_{j, 2010}^{m}\right|$, where $\ell_{j}$ is the employment share of occupation $j$.

In the outermost loop of the above procedure, note that we use occupation employment shares in aggregate. The industry-specific occupation weights $\nu_{i j}$ 's were recovered only from within industry employment shares by occupation. Once we have recovered all the parameters, we get $A_{i, 2010}$ 's to match measured productivity by sector in (16) to 
2010 data. ${ }^{14}$ Between 1980 and 2010, we assume that the $M_{j, t}$ 's, and all $A_{i, t}$ 's except $A_{I}$, grow at constant rates, so:

$$
\begin{aligned}
M_{j, t} & =M_{j, 1980}\left(M_{j, 2010} / M_{j, 1980}\right)^{(t-1980) / 30}, \\
A_{i, t} & =A_{i, 1980}\left(A_{i, 2010} / A_{i, 1980}\right)^{(t-1980) / 30}
\end{aligned}
$$

Lastly, the computer sector's exogenous productivity $\left(A_{I}\right)$ for other years are chosen so that the sectoral productivity of the computer sector in (16) is equal in the data and model.

\subsection{Properties of the Benchmark Model}

The calibration results are summarized in Tables 5 to 7 . Since changes in $M_{j}$ affect occupational employment across all industries, we can identify occupation-specific productivities separately from the sector-specific productivities. Specifically, occupational employment data alone gives enough information to identify the $M_{j}$ 's, from Equation (10). Given this, we can identify the sector-specific $A_{i}$ 's to fit measured sectoral productivities from the data using (16). The calibrated values for $M_{j}$ 's show that routine intensive occupations, such as machine operators or mechanics, indeed experienced much faster growth in their occupation-specific productivities. And as expected, the sector-specific productivity of the computer industry $\left(A_{I}\right)$ grew exceptionally fast especially during the 1990s.

\section{[ INSERT TABLES 4, 5, 6 AND 7 HERE ]}

It is also noteworthy that the $\rho_{i}$ 's are identified from how computer capital per worker $\left(s_{i}\right)$ and traditional capital per worker $\left(k_{i}\right)$ evolve differently across industries. Roughly speaking, when an industry that increases computers per worker more than other industries also uses more traditional capital per worker, the elasticity of substitution $\rho_{i}$ tends to be greater than one (Equation 15). But since traditional capital is a constant share of production in our model, our model admits $\rho_{i}>1$ for sectors whose output per worker increases with computers per worker. Since this is indeed the case for most industries in the data, as we saw in Figure 5, all calibrated $\rho_{i}$ 's are larger than $1 .^{15}$ This also implies that computerization leads to a decline in the labor share both at the sector and aggregate levels.

\section{[ INSERT FIGURE 6 HERE ]}

\footnotetext{
${ }^{14}$ We compute traditional and computer capital income shares, and measure sectoral productivity directly from the data. Hence, the model's sectoral output may differ from the data.

${ }^{15}$ Figure 5 shows that some small industries have a negative relationship in the data, but this is no longer the case once we aggregate the 60 industries into 10 more broadly defined sectors.
} 
In turn, sectors with higher computer per worker growth would also have higher values of $\rho_{i}$, as in Figure 6. This is illustrated in Figure 6(a), which plots computer per worker growth in the data against the $\rho_{i}$ 's. While panel (a) makes it clear how the relative values of $\rho_{i}$ are identified across sectors, note that the relationship is not exactly linear, even though the model fits computer capital per worker exactly by assumption as shown in panel (b) - since their empirical values are directly fed into step 1.ii of our calibration. This is because computers are not substituting labor directly, but only indirectly through the occupation composite $X_{i} \cdot{ }^{16}$

Model Fit The model-implied employment share changes fit the data better by occupation than by industry (Figure 7 ). This is because the $M_{j}$ 's directly affect occupational employment through (10), and once we match sectoral productivity growth by industry using (16), employment by industry is pinned down by (8).

\section{[ INSERT FIGURE 7 HERE ]}

This is also an indirect consequence of assuming constant $\sigma$ 's across all industries. Note that nowhere in our calibration did we separately target 2010 traditional capital per worker, nor employment share changes by industry. Our calibration step 1.ii and Equation (15) exploit all three factors at once, per industry, using only data on 2010 computer capital per worker by industry. This makes it clear that we can only let one of $\rho$ or $\sigma$ vary by sector. ${ }^{17}$ Both would affect how factor input ratios, and in particular computer capital per worker $s_{i}$, change across sectors in response to changes in $M_{j}$ 's. But one of our major goals is to quantitatively compare how aggregate productivity is affected by complementarity across occupations (shifts in $M_{j}$ through $\sigma$ ) relative to complementarity across industries (shifts in $A_{i}$ through $\epsilon$ ). How to implement such a comparison becomes less obvious if $\sigma$ 's vary across sectors.

More important, letting the elasticity of substitution between computers and labor $\left(\rho_{i}\right)$ vary across sectors directly captures how computer capital per worker evolves differentially across sectors, as we discussed above. If we were to instead let $\sigma$ vary, the effect is only indirect since computer-labor substitution would differ across sectors only due to differential shifts in relative labor demand. That is, unlike the clear relationship between $\rho_{i}$ and the growth of computer per worker $s_{i}$ as seen in Figure 6(a), there

\footnotetext{
${ }^{16}$ Related, since computers substitute a composite of labor rather than each occupation separately, the values of the substitutability parameters $\rho_{i}$ 's are potentially sensitive to $\sigma$, which measures the complementarity across occupations. We find that this is not the case for a wide range of values for $\sigma$ lower than its benchmark value, as shown in Appendix Table 8. While $\rho_{i}$ 's are sensitive to much larger values of $\sigma$, then it becomes impossible to fit other moments in the data (employment shares and TFP by industry).

${ }^{17}$ Since the $V_{i}$ 's are functions of $\sigma$.
} 
would be no systematic relationship between $\sigma$ and $s_{i}$ since it would also depend on the sector-specific occupation weights $\nu_{i j}$ 's.

Thus, our exact fit to computer capital per worker growth, to some extent, comes at the expense of a lesser fit to employment share changes and traditional capital per worker growth by industry. See Figures $7(\mathrm{~b})$ and $8(\mathrm{~b})$. This indicates that the unit elasticity assumption between traditional capital and other factors, and also the assumption that the elasticity is constant across sectors, may be too stringent. Still, both changes in employment shares and traditional capital per worker by industry are qualitatively consistent with the data.

\section{[ INSERT FIGURES 8 AND 9 HERE ]}

More assuringly, even though we did not use any data on output per worker growth - neither by industry nor in aggregate - nor aggregate productivity, the model prediction of output per worker growth by industry is remarkably close to the data, Figure 8(a). Most importantly for our purposes, the model generates a slowdown in aggregate output and productivity growth starting in 2000 , similarly as in the data, as shown in Figure 9 and tabulated in Appendix Table 9. The fit to aggregate productivity is especially remarkable considering that we assume constant productivity growth rates for $M_{j}$ and $A_{i}$-other than $A_{I}$-and do not target any aggregate variables in 2010 .

\section{[ INSERT FIGURE 10 HERE ]}

Lastly, the model-implied factor income shares by industry are also generally consistent with the data (Appendix Figure 17). Partly because of this, the aggregate labor share in the model closely tracks the trend in the data, both in direction and magnitude (Figure 10), despite not being targeted at all at the sectoral nor aggregate levels. Recall that our production technology assumes that traditional capital's income share is constant by construction. Thus, our results suggest that computer hardware and software, which are a subset of total capital that accounts for 14 percent of all investment, can be responsible for the vast majority of the fall in the labor share (4 out of 5 percentage points) since $1980 .^{18}$

\footnotetext{
${ }^{18}$ As a direct consequence of not fitting capital per worker growth by sector, the model fit to the fall in labor shares by sector is poorer than in aggregate. Aggregate capital per worker $k$ in the data is directly fed into the model.
} 


\subsection{Counterfactual Analysis}

In this section, we investigate the underlying factors that shape aggregate output and productivity, focusing on routinization and computerization. Routinization in our model is a faster increase in the occupation-speciifc productivity, $M_{j}$, of certain occupations. Computerization is driven by the computer industry-specific term, $A_{I}$, which propagates through all industries because computer capital is used in the production of all industrial goods.

In our model equilibrium, this propagation happens by shifting the price of computer capital. High $A_{I}$ shrinks the computer sector employment because of complementarity, but also lowers the relative price of computers. This, in turn, leads to a drop in the rental rate of computer capital, which induces all sectors to use more computers. This prevents the computer sector from shrinking.

Aggregate productivity Note that the growth rates of occupation- and sectorspecific productivities $\left(M_{j}\right.$ and $\left.A_{i}\right)$ were assumed to be constant for the entire sample period except for the computer sector's $\left(A_{I}\right)$. Nonetheless, in the benchmark calibration, aggregate TFP increases almost linearly from 1980 to 2000, slowing down in the last decade (Figure 11). ${ }^{19}$ We now show that the high growth rate of the computer sector-specific productivity $\left(A_{I}\right)$ prevented a potential slowdown in aggregate productivity that would have appeared between 1990 and 2000. Figure 11 shows that, if we assume $A_{I}$ were constant between 1980 and 2010, aggregate productivity growth would have slowed down since 1990. Without the growth in $A_{I}$, aggregate productivity would have grown by only 13 percent from 1980 to 2010, one-third lower than the benchmark growth rate of 20 percent over the same period. This magnitude is surprising considering the fact that the computer sector's share of aggregate output is only 3 to 4 percent throughout the observation period.

\section{[ INSERT FIGURE 11 HERE ]}

When all occupation- and sector-specific productivities grow at constant rates over time, complementarity across jobs and sectors induces the faster growing jobs and sectors to shrink in relative size, reducing their weights in the computation of aggregate productivity. Hence, as long as occupation- and sector-specific productivities grow at different rates, aggregate productivity growth must slow down over time. So both the dispersions in the growth rates of occupation-specific productivities $\left(M_{j}\right)$ and in sectorspecific productivities $\left(A_{i}\right.$ 's) contribute to the aggregate productivity slowdown. To

\footnotetext{
${ }^{19}$ Aggregate productivity growth is measured as $d \log (y)-($ traditional capital share) $\cdot d \log (k)-$ (computer share) $\cdot d \log (s)$.
} 
find out which dispersion is more important for the slowdown, we conduct the following exercises.

\section{[ INSERT FIGURE 12 HERE ]}

In the first exercise, we force all $M_{j}$ 's to grow at the same rate $m$ for all $j$ (i.e., no routinization) while leaving the growth rates of $A_{i}$ 's to be different from one another as in the benchmark. Second, we force all $A_{i}$ 's to grow at a common rate $a$ while leaving the growth rates of $M_{j}$ 's heterogeneous as in the benchmark. The common growth rates $m$ and $a$ are set so that aggregate productivity grows at the same rate as in the first decade of our benchmark calibration. The results are shown in Figure 12. According to this exercise, routinization, or the dispersion in the growth rates of $M_{j}$, is more important in explaining the decline in the growth rate of aggregate productivity. ${ }^{20}$ Without routinization, the growth rate of aggregate productivity remains near 0.8 percent per year throughout the three decades. In contrast, even when all sectorspecific productivities grow at a common rate, aggregate productivity growth falls almost as much as in the benchmark. Of course for the latter exercise, we are also ruling out the faster growth of the computer sector, which partially explains the gap between the benchmark growth rate and this counterfactual growth rate in the 1990s.

Output Fast-growing computer sector-specific productivity directly boosts aggregate productivity, which leads to an acceleration of aggregate output growth. Furthermore, there is an additional effect on aggregate output, since all sectors use more computer capital. Figure 13 shows the total effect of computerization on aggregate output. If $A_{I}$ were to remain constant between 1980 and 2010, aggregate output growth from 1980 to 2010 would be 63 percent, or only about half of the growth in the benchmark. As expected, this is a larger impact than that on aggregate productivity.

\section{[ INSERT FIGURE 13 HERE ]}

Figure 14 shows output growth by industry with and without $A_{I}$ growth. Due to the substitutability between computer and labor, all industries benefit from computerization. Unsurprisingly, the computer industry itself is affected the most, followed by finance and high-skilled services. The construction industry has the least to gain (in terms of output growth) from computerization.

\section{[ INSERT FIGURE 14 HERE ]}

\footnotetext{
${ }^{20}$ Of course, this result also depends on our specific framework that assumes constant 30-year growth rates for all $M_{j}$ 's and $A_{i}$ 's.
} 
Labor share Because the model calibration yields sector-specific elasticities of substitution between labor and computer capital $\left(\rho_{i}\right)$ that are larger than 1, computerization results in the decline of labor shares in all sectors. Figure 15 shows changes in labor shares by industry for various counterfactual exercises. Among all these exercises, the only two that affect labor shares are when we eliminate computerization either explicitly (in red); or by assuming common growth rates across all industries (in sky-blue). So we can conclude that the growth in $A_{I}$ is the only important driving force behind the decline of the labor share.

\section{[ INSERT FIGURE 15 HERE ]}

Computer capital in the measurement of TFP In our benchmark, we measured aggregate productivity growth between times $s$ and $t$ as follows:

$$
\log \left(\frac{A_{t}}{A_{s}}\right)=\log \left(\frac{Y_{t}}{Y_{s}}\right)-\bar{\theta}^{L} \log \left(\frac{L_{t}}{L_{s}}\right)-\bar{\theta}^{S} \log \left(\frac{S_{t}}{S_{s}}\right)-\bar{\theta}^{K} \log \left(\frac{K_{t}}{K_{s}}\right),
$$

where $\bar{\theta}^{L}$ is labor income share, $\bar{\theta}^{S}$ is computer capital income share, and $\bar{\theta}^{K}$ is traditional capital income share on average between time $s$ and $t$. But typically, the standard way we compute TFP growth (the Solow residual $\hat{A}$ ) is

$$
\log \left(\frac{\hat{A}_{t}}{\hat{A}_{s}}\right)=\log \left(\frac{Y_{t}}{Y_{s}}\right)-\bar{\theta}^{L} \log \left(\frac{L_{t}}{L_{s}}\right)-\left(\bar{\theta}^{K}+\bar{\theta}^{S}\right) \log \left(\frac{K_{t}+S_{t}}{K_{s}+S_{s}}\right) .
$$

Note that $A_{t}$ and $\hat{A}_{t}$ can differ, especially when the gross rate of return on computer capital and traditional capital are different. By inspection of (17), we see that this happens when either the investment prices and/or the depreciation rates of the two types of capital differ. In particular, the gross rate of return on computer capital is generally higher than traditional capital because the former depreciates more quickly. This implies that the standard way of computing TFP without separating out computer capital will overestimate the growth rate of aggregate productivity.

In Figure 16, we compare aggregate productivity from our benchmark calibration $(A)$ against the TFP (standard Solow residual, $\hat{A}$ ), both according to our model (panel a) and in the data (panel b). For panel (a), we plug in our model-simulated data into (18). For panel (b), we impute all variables needed in (18) directly from the data. The figure confirms that the aggregate productivity growth is overestimated by about 10 percentage points over the past 30 years if computer capital is not explicitly separated, both in the data and also according to our model.

\section{[ INSERT FIGURE 16 HERE ]}


Summary of quantitative analysis There are two main findings from our quantitative analysis. First, constant occupation- and sector-specific technological progress necessarily slows down aggregate productivity growth over time, given complementarity across jobs and industries. Second, it was the dispersion in the growth rates across occupations (i.e., routinization) that was most responsible for the aggregate productivity slowdown. This negative impact of routinization on the growth rate of aggregate productivity was more or less perfectly counterbalanced by the impressive technological progress specific to the computer industry and its spillover through inter-industry linkages during the 1980s and the 1990s. The slower pace of the computer sector's productivity growth in recent years - and the associated deceleration of computer usage by other industries since 2000 - is finally revealing the negative impact that decades of routinization has had on aggregate productivity growth.

\section{Concluding Remarks}

In the model we presented, productivities grow at heterogeneous rates across occupations (routinization), and also across industries. In particular, to understand the effect of the rise of the computer industry on aggregate productivity, we let its output be used in the production of all industries as a distinct type of capital.

We showed that when occupations and industries are complementary to one another and occupation- and sector-specific productivities grow at different rates, routinization in particular causes a slowdown in aggregate productivity. But such a slowdown was averted prior to the 2000s in the U.S., thanks to the rapid rise of the computer industry's productivity. It was only after the productivity of this sector slowed down that routinization began to reveal its negative impact on aggregate productivity growth.

The main message of our model is that multiple layers of the economy (i.e., occupations and sectors) can interact to generate interesting time trends that can help us reconcile evidence at the occupation and sector levels with aggregate trends. Moreover, we have also highlighted the importance of inter-industry linkages by showcasing that a single industry - in our case the computer industry - can have large effects on aggregate variables once such a propagation mechanism is taken into account.

In reality, all industries are interlinked, not only by providing intermediate inputs to one another as emphasized in some recent models (Acemoglu, Carvalho, Ozdaglar, and Tahbaz-Salehi, 2012; Atalay, 2017) but also by serving different types of capital in which all industries need to invest (as we have modeled here). Modeling such additional layers of complexity is left for future research. 


\section{References}

Acemoglu, D., D. Autor, D. Dorn, G. H. Hanson, and B. Price (2014, May). Return of the Solow paradox? IT, productivity, and employment in US manufacturing. American Economic Review 104(5), 394-99.

Acemoglu, D., V. M. Carvalho, A. Ozdaglar, and A. Tahbaz-Salehi (2012). The network origins of aggregate fluctuations. Econometrica 80(5), 1977-2016.

Atalay, E. (2017, October). How important are sectoral shocks? American Economic Journal: Macroeconomics 9(4), 254-80.

Aum, S. (2017). The rise of software and skill demand reversal. Manuscript.

Aum, S., S. Y. T. Lee, and Y. Shin (2017). Industrial and occupational employment changes during the Great Recession. Federal Reserve Bank of St. Louis Review 99(4), $307-317$.

Autor, D. H. and D. Dorn (2013). The growth of low-skill service jobs and the polarization of the US labor market. American Economic Review 103(5), 1553-97.

Baumol, W. J. (1967). Macroeconomics of unbalanced growth: The anatomy of urban crisis. The American Economic Review 57(3), 415-426.

Byrne, D. M., J. G. Fernald, and M. B. Reinsdorf (2016). Does the United States have a productivity slowdown or a measurement problem? Brookings Papers on Economic Activity 47(1 (Spring), 109-182.

Cortes, G. M., N. Jaimovich, and H. E. Siu (2017). Disappearing routine jobs: Who, how, and why? Journal of Monetary Economics.

Duernecker, G., B. Herrendorf, and A. Valentinyi (2017). Structural change within the service sector and the future of Baumol's disease.

Goos, M., A. Manning, and A. Salomons (2014). Explaining job polarization: Routinebiased technological change and offshoring. American Economic Review 104(8), 2509-26.

Karabarbounis, L. and B. Neiman (2014). The global decline of the labor share. The Quarterly Journal of Economics 129(1), 61-103. 
Koh, D., R. Santaeullia-Llopis, and Y. Zheng (2016, September). Labor share decline and intellectual property products capital. Working Papers 927, Barcelona Graduate School of Economics.

Lee, S. Y. T. and Y. Shin (2017). Horizontal and vertical polarization: Task-specific technological change in a multi-sector economy. Working Paper 23283, NBER.

Ngai, L. R. and C. A. Pissarides (2007, March). Structural change in a multisector model of growth. American Economic Review 97(1), 429-443.

Syverson, C. (2017, May). Challenges to mismeasurement explanations for the US productivity slowdown. Journal of Economic Perspectives 31(2), 165-86. 


\begin{tabular}{ll}
\hline \multicolumn{1}{c}{ Industry } & \multicolumn{1}{c}{ BEA industry code } \\
\hline Mining & $211,212,213$ \\
Construction & 23 \\
Durable goods manufacturing & $311 \mathrm{FT}, 313 \mathrm{TT}, 315 \mathrm{AL}, 322,323,324,325,326$ \\
Non-durable goods manufacturing & $321,327,331,332,333,335,3361 \mathrm{MV}, 3364 \mathrm{OT}, 337,339$ \\
FIRE & $521 \mathrm{CI}, 523,524,531,532 \mathrm{RL}$ \\
Health & $621,622 \mathrm{HO}$ \\
Other high-skill services & $512,513,514,5411,5412 \mathrm{OP}, 5415,55,61$ \\
Trade (Retail \& Wholesale) & $42,44 \mathrm{RT}$ \\
Other low-skill services & $22,481,482,483,484,485,486,487 \mathrm{OS}, 493,561,562,624$, \\
& $711 \mathrm{AS}, 713,721,722,81$ \\
\hline Computer & 334,511 \\
\hline
\end{tabular}

Table 1: Industry classification

Refer to BEA Industry Accounts for names of industries. The computer industry comprises hardware (computer and electronic products) and software (publishing industries). 


\begin{tabular}{lc}
\hline \multicolumn{1}{c}{ Occupation } & Occupation code \\
\hline High skill & $4-37$ \\
Management & $43-199$ \\
Professionals & \\
\hline Middle skill & $503-599$ \\
Mechanics \& Construction & $614-699$ \\
Miners \& Precision workers & $203-235$ \\
Technicians & $243-283$ \\
Sales & $803-889$ \\
Transportation & $703-799$ \\
Machine operators & $303-389$ \\
Administrative support & $405-498$ \\
\hline Low skill services &
\end{tabular}

Table 2: Occupation classification

Consistent occupation code (occ1990dd) constructed following Autor and Dorn (2013). 


\begin{tabular}{cc}
\hline Parameters & Estimates \\
\hline$\epsilon$ & $0.765^{* * *}(0.002)$ \\
\hline$\gamma_{1}$ & $0.084^{* * *}(0.001)$ \\
$\gamma_{2}$ & $0.159^{* * *}(0.002)$ \\
$\gamma_{3}$ & $0.099^{* * *}(0.003)$ \\
$\gamma_{4}$ & $0.124^{* * *}(0.002)$ \\
$\gamma_{5}$ & $0.142^{* * *}(0.001)$ \\
$\gamma_{6}$ & $0.087^{* * *}(0.002)$ \\
$\gamma_{7}$ & $0.057^{* * *}(0.002)$ \\
$\gamma_{8}$ & $0.094^{* * *}(0.003)$ \\
$\gamma_{9}$ & $0.117^{* * *}(0.002)$ \\
\hline AIC & \multicolumn{2}{c}{-1001.432} \\
\hline
\end{tabular}

Table 3: Estimation results

Standard errors in parentheses. ${ }^{*} p<0.10,{ }^{* *} p<0.05,{ }^{* * *} p<0.01$ 


\begin{tabular}{ccl}
\hline Parameters & Value & Obtained from \\
\hline$\sigma$ & 0.815 & Mean absolute distance of the changes in the employment share \\
$r+\delta_{S}$ & 0.300 & Average depreciation rate of computer capital from FAT \\
\hline
\end{tabular}

Table 4: Calibrated parameters 


\begin{tabular}{|c|c|c|c|c|c|c|c|c|c|c|}
\hline Param/Target & Const & FIRE & Health & $\begin{array}{l}\text { High } \\
\text { serv. }\end{array}$ & $\begin{array}{l}\text { Low } \\
\text { serv. }\end{array}$ & Dur & Mine & $\begin{array}{l}\text { Non- } \\
\text { durable }\end{array}$ & Trade & $\begin{array}{l}\text { Comp- } \\
\text { uter }\end{array}$ \\
\hline outside & . & 0150 & 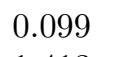 & 0 & 0.17 & & & 4 & 0 & 37 \\
\hline$s_{i, 2010}$ & .699 & 1.213 & 1.413 & 1.461 & 5 & 1.2 & 5 & 59 & 1. & 1.840 \\
\hline$\omega \quad s_{i, 1980}$ & .001 & 0.0 & 0.003 & 0.025 & 0.006 & 0.0 & 0 & 0.009 & 0.008 & 0.020 \\
\hline$\alpha \quad k_{i, 1980}$ & .167 & 0.374 & 0.301 & 0.454 & 0.475 & 0.333 & 0.793 & 0.402 & 0.186 & 0.322 \\
\hline
\end{tabular}

Table 5: Industry specific parameters

Industry weights $\gamma_{i}$ and the computer industry's traditional capital income share $\alpha_{I}$ are estimated directly from the data using the BEA Industry Accounts and FAT, while the rest are calibrated according to a method of moments. See text for details. 


\begin{tabular}{lrrrrrrrrrr}
\hline & L serv. & Admin. & Mach & Sales & Trans & Tech & Mech & Mine. & Prof. & Mngm \\
\hline Const & 0.009 & 0.058 & 0.027 & 0.009 & 0.218 & 0.016 & 0.564 & 0.015 & 0.021 & 0.061 \\
FIRE & 0.048 & 0.444 & 0.005 & 0.225 & 0.015 & 0.014 & 0.013 & 0.004 & 0.021 & 0.211 \\
Health & 0.328 & 0.172 & 0.005 & 0.004 & 0.006 & 0.122 & 0.009 & 0.011 & 0.293 & 0.050 \\
H serv. & 0.109 & 0.222 & 0.010 & 0.020 & 0.022 & 0.043 & 0.037 & 0.007 & 0.420 & 0.110 \\
L serv. & 0.375 & 0.143 & 0.025 & 0.041 & 0.129 & 0.012 & 0.080 & 0.023 & 0.070 & 0.101 \\
Durable & 0.022 & 0.115 & 0.372 & 0.021 & 0.102 & 0.027 & 0.081 & 0.136 & 0.049 & 0.076 \\
Mining & 0.017 & 0.103 & 0.047 & 0.010 & 0.195 & 0.051 & 0.121 & 0.311 & 0.065 & 0.080 \\
Non-dur & 0.028 & 0.118 & 0.386 & 0.039 & 0.135 & 0.023 & 0.050 & 0.106 & 0.036 & 0.079 \\
Trade & 0.025 & 0.150 & 0.022 & 0.406 & 0.152 & 0.005 & 0.066 & 0.042 & 0.022 & 0.110 \\
Computer & 0.016 & 0.165 & 0.310 & 0.059 & 0.042 & 0.062 & 0.041 & 0.070 & 0.124 & 0.111 \\
\hline
\end{tabular}

Table 6: Industry-occupation specific weights on labor $\left(\nu_{i j}\right)$

Calibration results for $\nu_{i j}$ from a method of moments. Empirical targets are within-industry employment shares by occupation in 1980 . 


\begin{tabular}{lcccc|llllll}
\hline \multicolumn{3}{l}{ Target: emp. share by ind. and occ. in 2010} & \multicolumn{5}{|c}{ Target: measured productivity in 1980 and 2010} \\
$M_{j}$ & 1980 & 1990 & 2000 & 2010 & $A_{i}$ & 1980 & 1990 & 2000 & 2010 \\
\hline Low serv. & 1.000 & 1.000 & 1.000 & 1.000 & Const & 14.125 & 10.394 & 7.648 & 5.628 \\
Admin. & 1.000 & 1.384 & 1.914 & 2.649 & FIRE & 17.924 & 17.267 & 16.633 & 16.023 \\
Machine & 1.000 & 2.273 & 5.168 & 11.749 & Health & 6.155 & 6.460 & 6.780 & 7.115 \\
Sales & 1.000 & 0.590 & 0.348 & 0.205 & High serv. & 1.385 & 1.624 & 1.904 & 2.232 \\
Trans & 1.000 & 1.263 & 1.595 & 2.014 & Low serv. & 0.050 & 0.053 & 0.057 & 0.060 \\
Tech & 1.000 & 0.736 & 0.542 & 0.399 & Durable & 0.198 & 0.191 & 0.185 & 0.179 \\
Mechanics & 1.000 & 1.610 & 2.591 & 4.171 & Mining & 3.048 & 3.104 & 3.161 & 3.219 \\
Mine. & 1.000 & 1.444 & 2.085 & 3.010 & Non-durable & 0.701 & 0.708 & 0.716 & 0.724 \\
Prof. & 1.000 & 0.553 & 0.306 & 0.169 & Trade & 0.269 & 0.373 & 0.516 & 0.714 \\
Mngm & 1.000 & 0.461 & 0.212 & 0.098 & Computer & 1.945 & 3.667 & 13.624 & 26.618 \\
\hline
\end{tabular}

Table 7: Occupation- and sector-specific productivity

Occupation-specific productivities are normalized to 1 in 1980. For 2010, we minimize the distance between the model and data on within-industry employment shares by occupation averaged across all industries in the IPUMS Census. The computer industry's 1980 sector-specific productivity is chosen to minimize the distance between model and data on its real value-added per worker in the BEA Industry Accounts, while all other industries' productivities are implied by the model and data on capital and labor data relative to the computer sector from the Industry Accounts and FAT. All sector-specific productivities in 2010 are recovered from our expression for sectoral productivity in (16), using the Industry Accounts data and our calibrated parameters. Except for the computer sector-specific productivity $A_{I}$, all $A_{i}$ 's are assumed to grow at a constant rate from 1980 to 2010. 


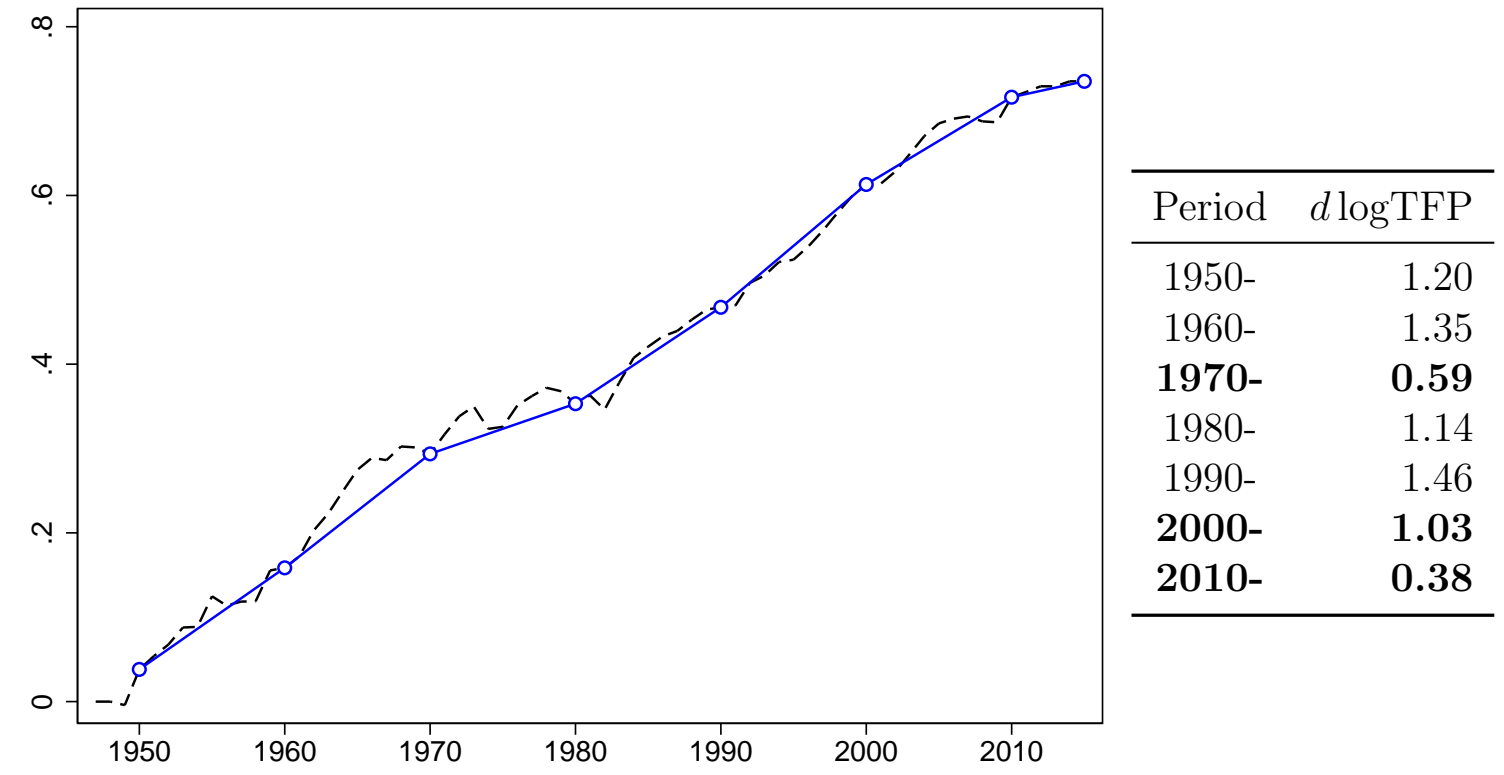

Fig. 1: Log aggregate TFP

Source: National Income and Product Accounts (NIPA) from the Bureau of Economic Analysis (BEA). TFP is measured as the Solow residual assuming a homogeneous of degree one production function with two factors, capital and labor. 


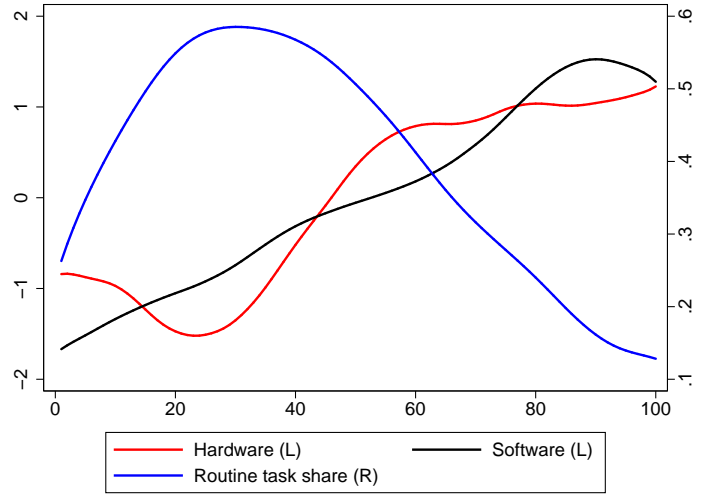

(a) Routinization and computerization

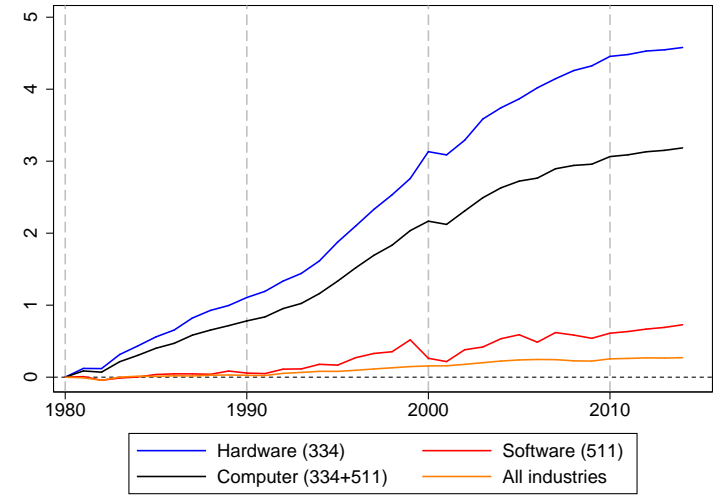

(b) log-TFP of computer industry

Fig. 2: PC use by occupation and PC industry TFP

Source: (a) IPUMS Census, BEA NIPA and O*NET. (b) BEA Industry Accounts. The computer industry includes industries 334 and 511 (for hardware and software, respectively). See footnote 8 and text for the data and accounting behind the graphs. 


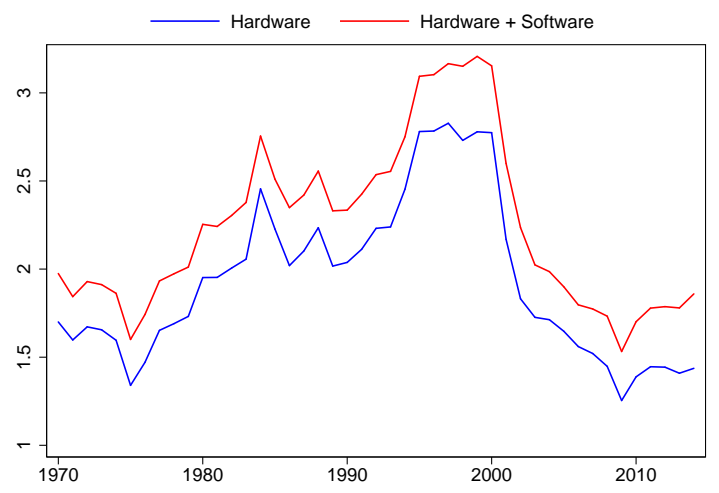

(a) Computer share of intermediates (\%)

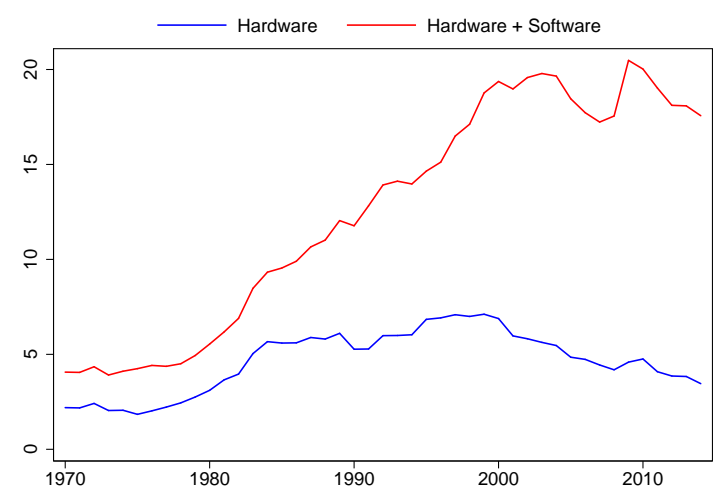

(b) Computer share of non-residential investment (\%)

\section{Fig. 3: Computer use in production over time}

Source: BEA Input-Output Tables and Fixed Asset Tables (FAT). In panel (a), hardware and software are industries 334 and 511. In panel (b), hardware and software are investments into "computers and peripheral equipment" and "software" in the FAT. 


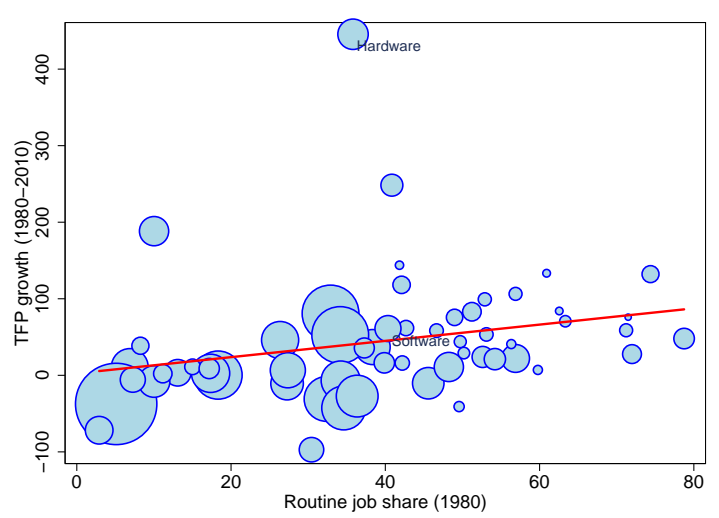

(a) Routine occupation share and TFP growth

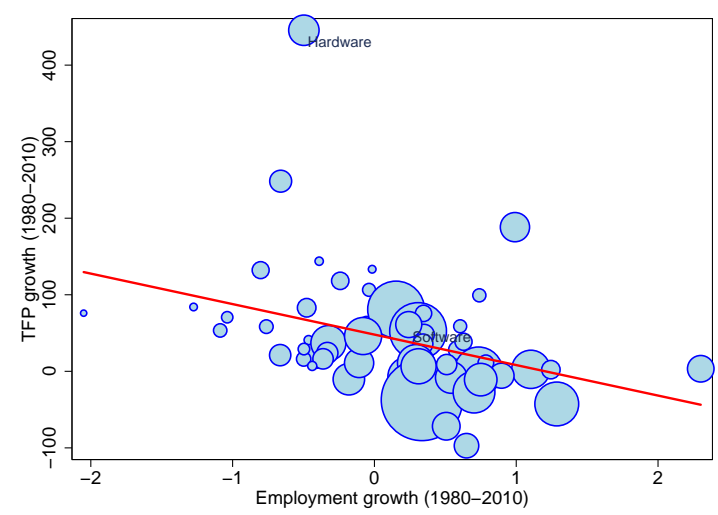

(b) TFP and employment growth across industries

Fig. 4: Routinization and industry TFP and employment

Source: IPUMS Census and BEA Industry Accounts. Hardware and Software are industries 334 and 511, respectively. In panel (a), routine jobs are defined as occupations above the 66 percentile in terms of the RTI index (Autor and Dorn, 2013). In panel (b), FTPT is full-time plus part-time workers. 


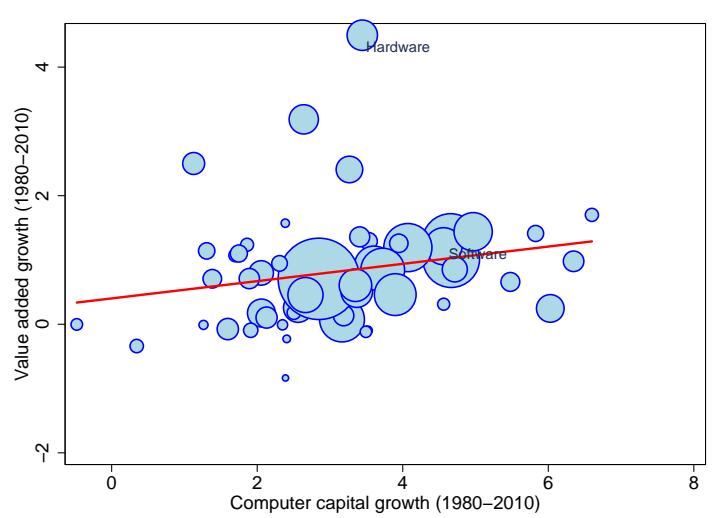

(a) Hardware

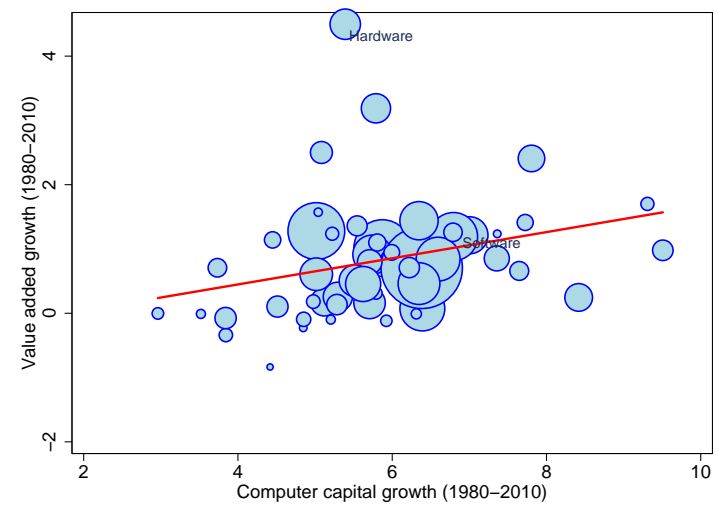

(b) Software

Fig. 5: Growth of value-added output and computer capital

Source: BEA Industry Accounts and FAT Nonresidential Detailed Estimates by Industry and Type. Hardware and Software are industries 334 and 511, respectively. Hardware capital is the net stock of "computers and peripheral equipment" and software capital the net stock of "software" by industry. 


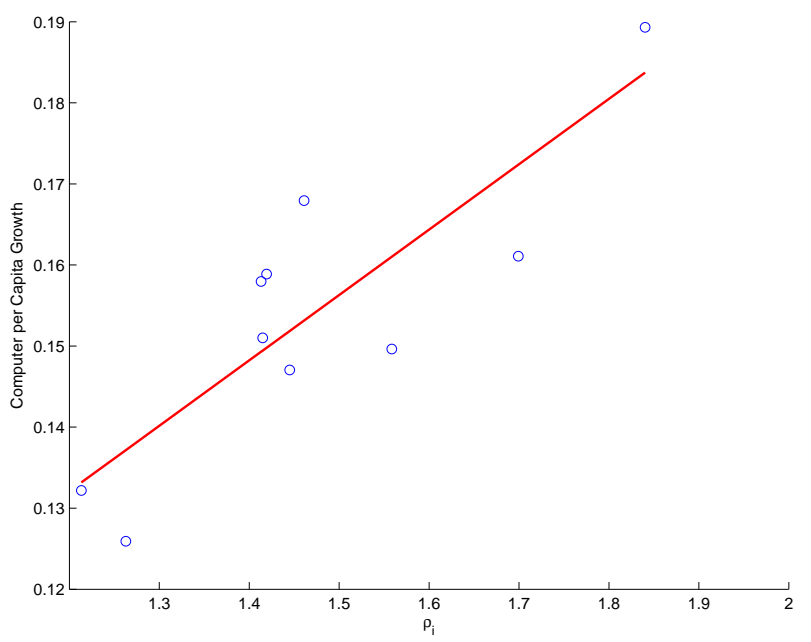

(a) Data against computer-worker substitutability $\rho_{i}$

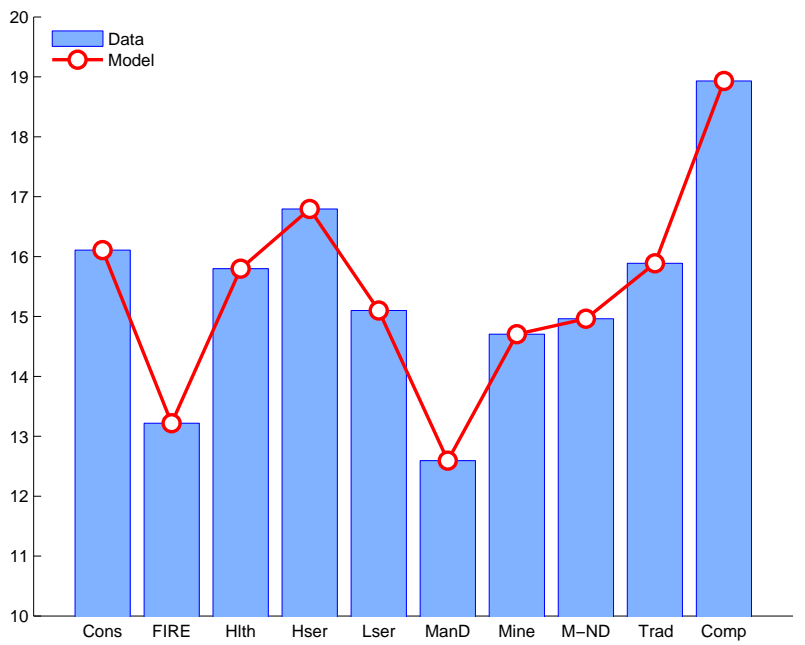

(b) Computer capital per worker

Fig. 6: Computer per worker growth between 1980 and 2010

Source: BEA Industry Accounts and FAT. See Table 1 for details of the industry classification. Computer capital is measured as the sum of "computers and peripheral equipment" and "software" by industry, available in FAT Table 3.1. 


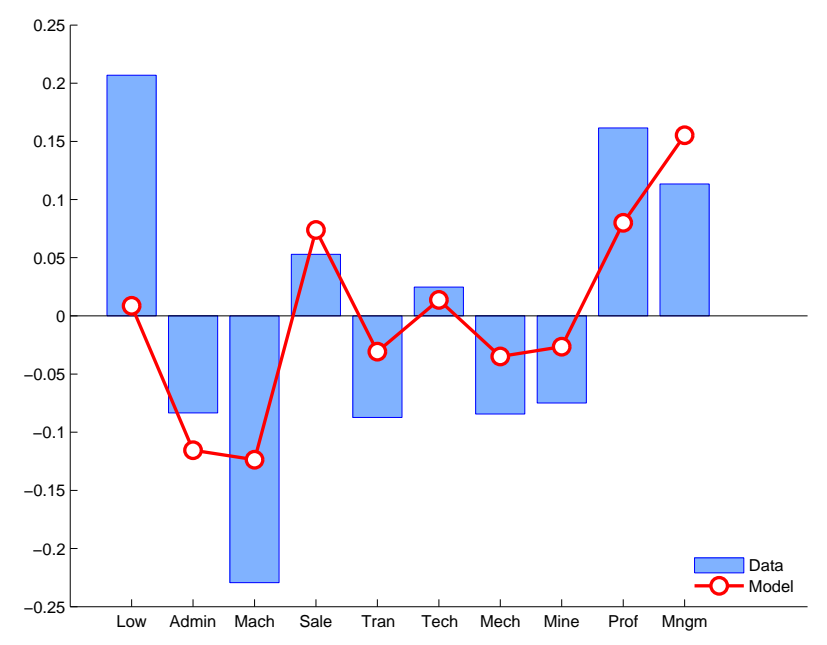

(a) By occupation

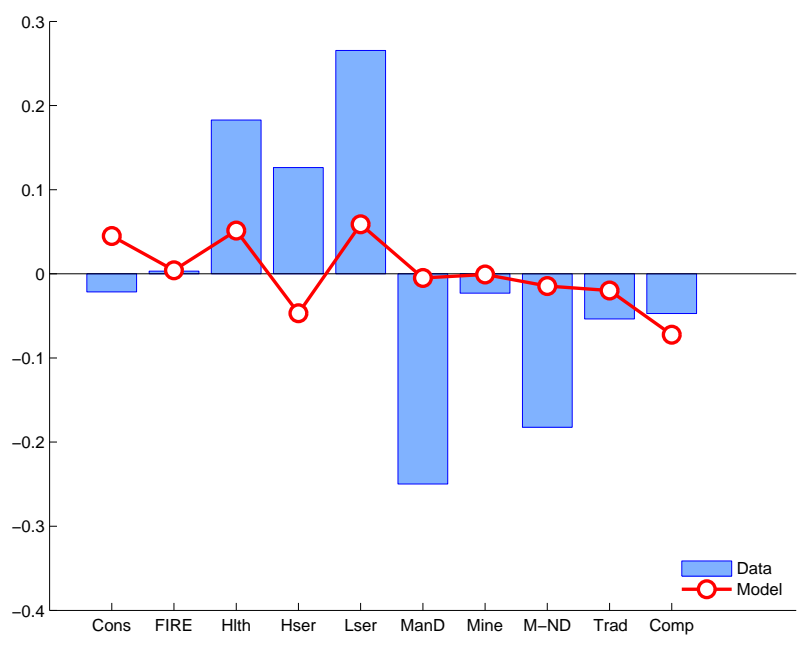

(b) By industry

Fig. 7: Changes in employment shares between 1980 and 2010

Data Source: occupation data are from IPUMS Census, and industries from BEA Industry Accounts. See Table 2 for details of the occupation classification. 


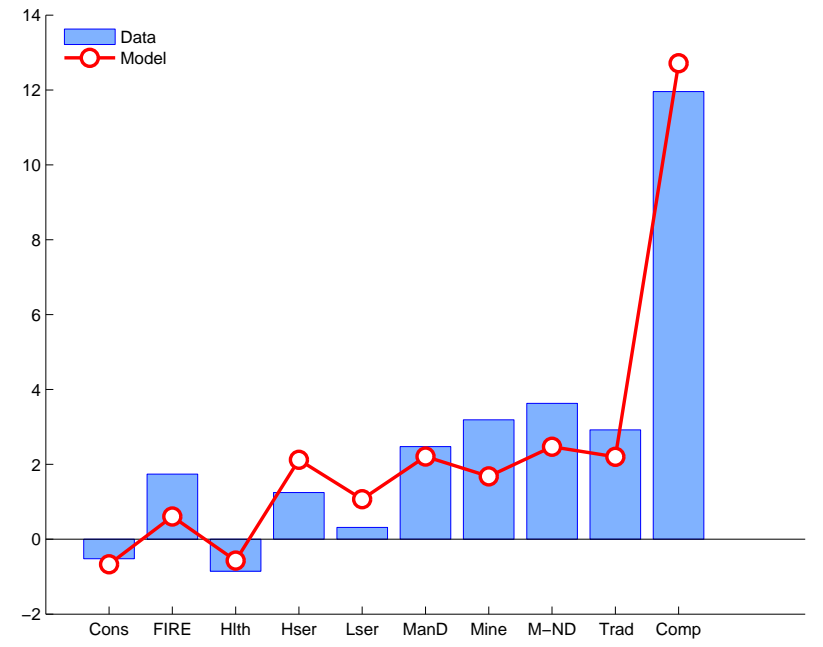

(a) Output per worker

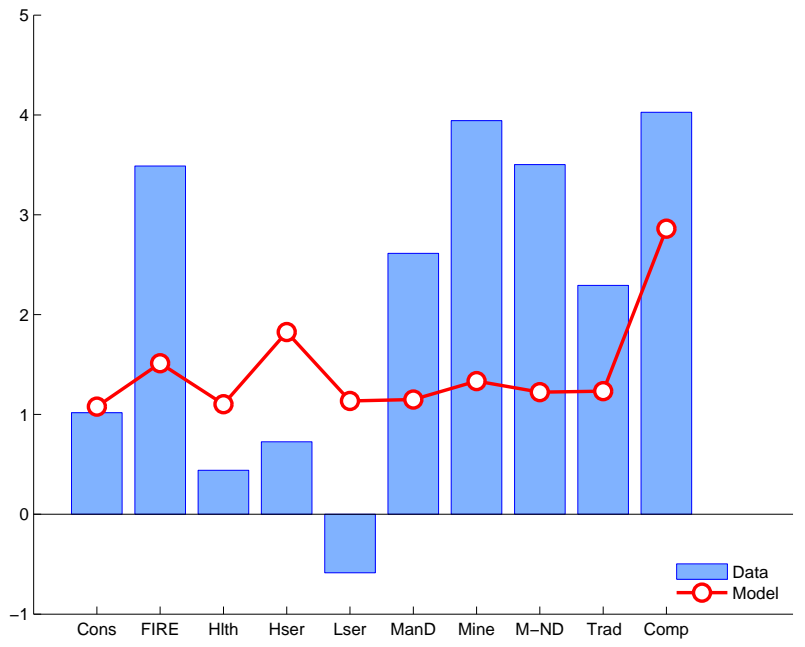

(b) Tradition capital per worker

Fig. 8: Log changes of output and capital per worker between 1980 and 2010 Data Source: BEA Industry Accounts and FAT. See Table 1 for details of the industry classification. 


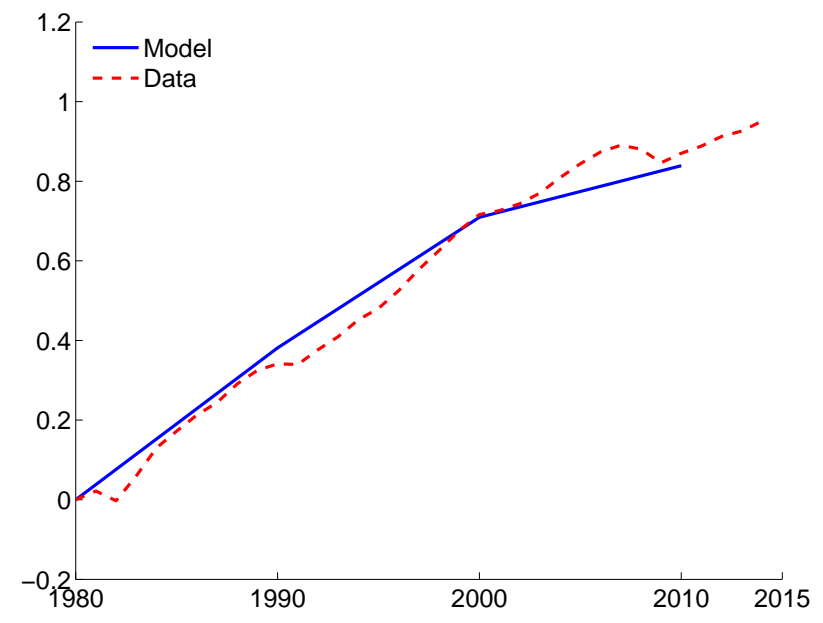

(a) Output

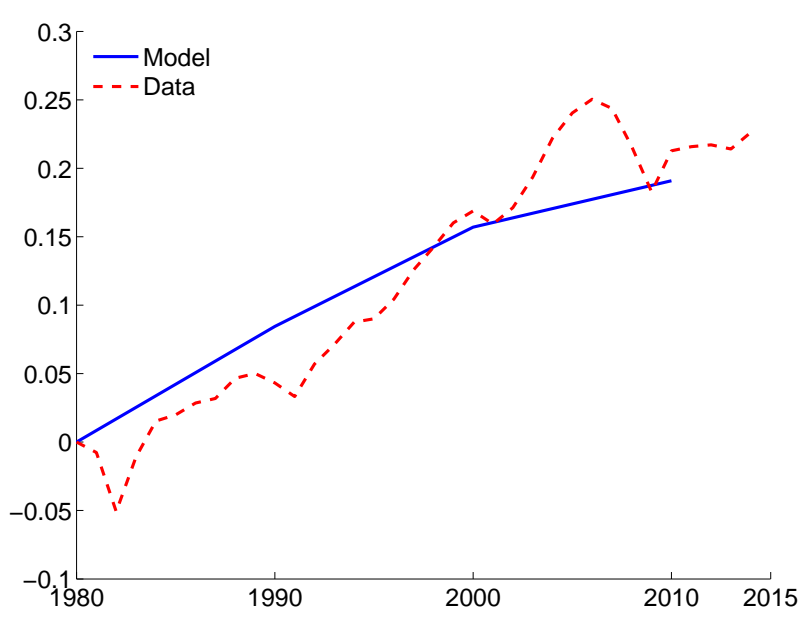

(b) Productivity

Fig. 9: Aggregate production

Data Source: BEA NIPA. Exact numbers for the plots are tabulated in Appendix Table 9. 


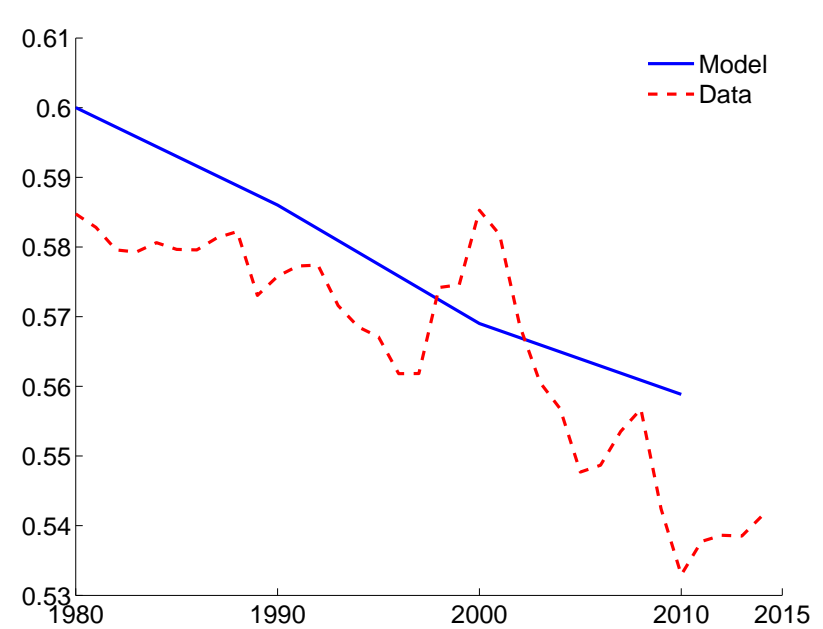

(a) Aggregate

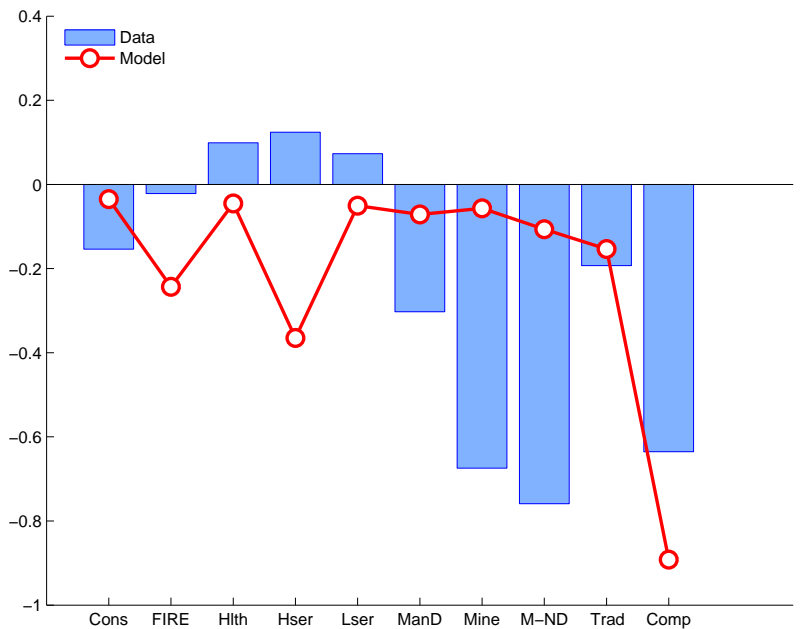

(b) By industry

Fig. 10: Changes in labor share: Model vs. data

Data Source: BEA NIPA and Industry Accounts. See Table 1 for details of the industry classification. 


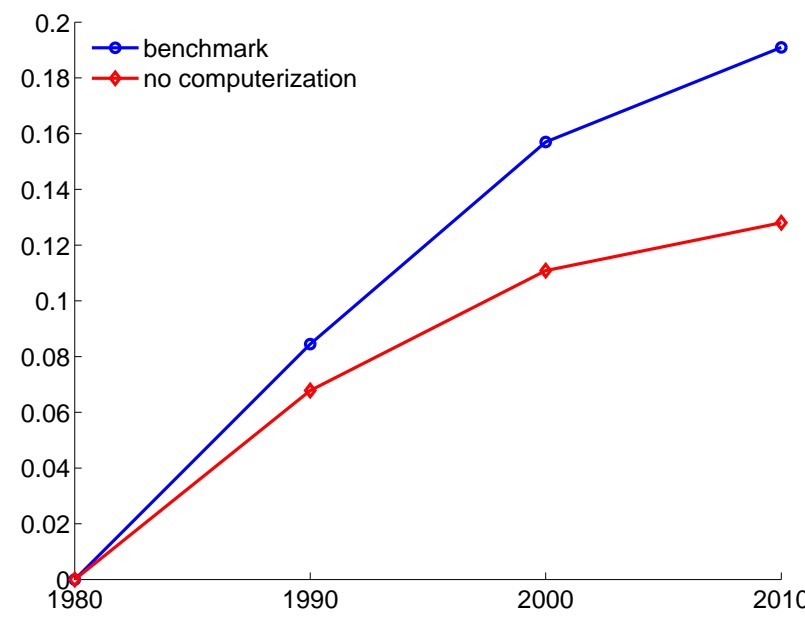

(a) Log level

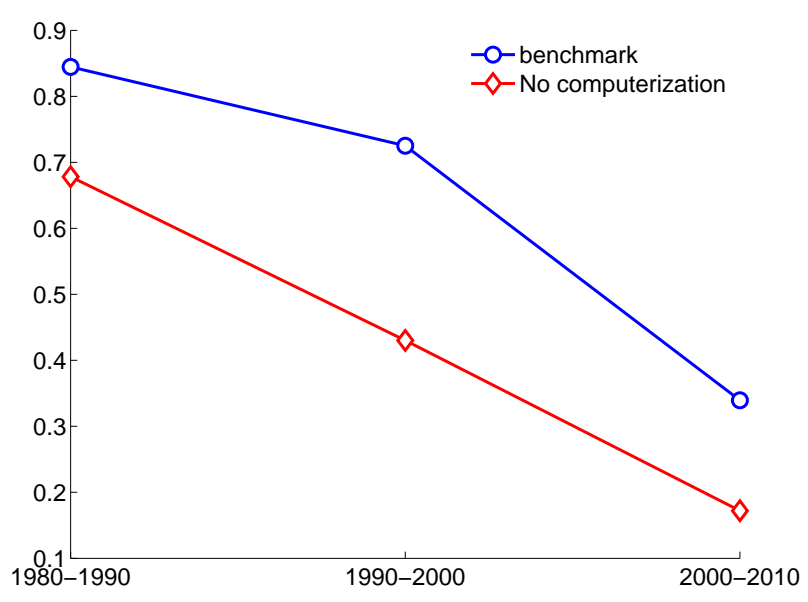

(b) Growth rate

Fig. 11: Aggregate productivity without computerization 


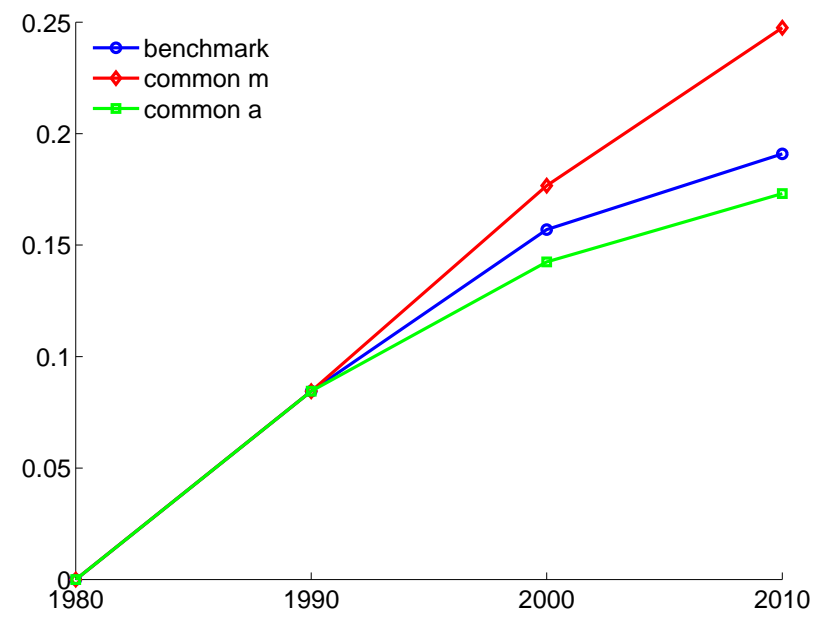

(a) Log level

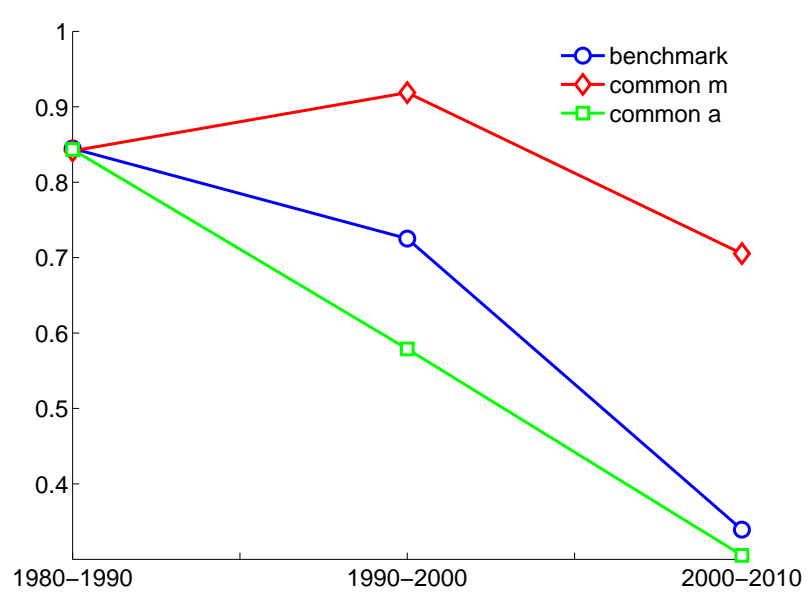

(b) Growth rate

Fig. 12: Aggregate productivity without complementarity 


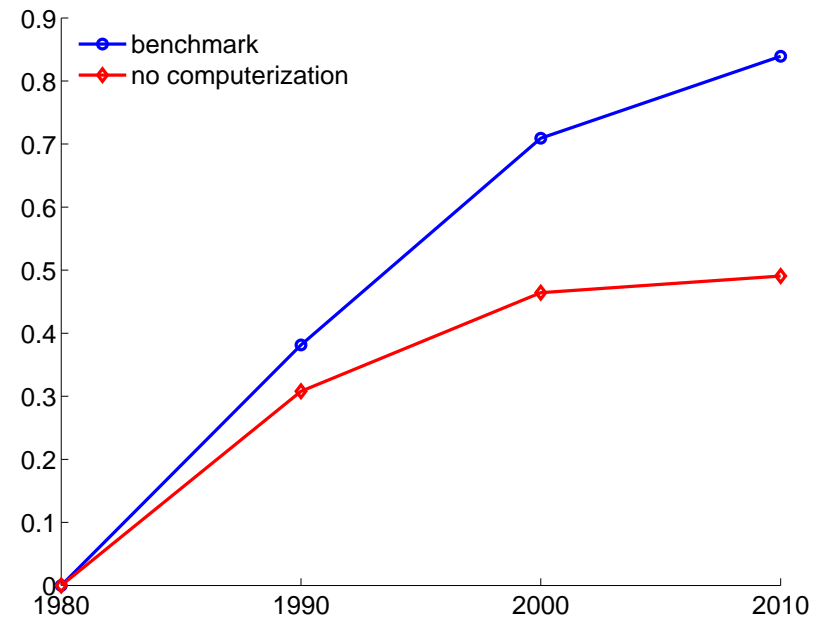

(a) Log level

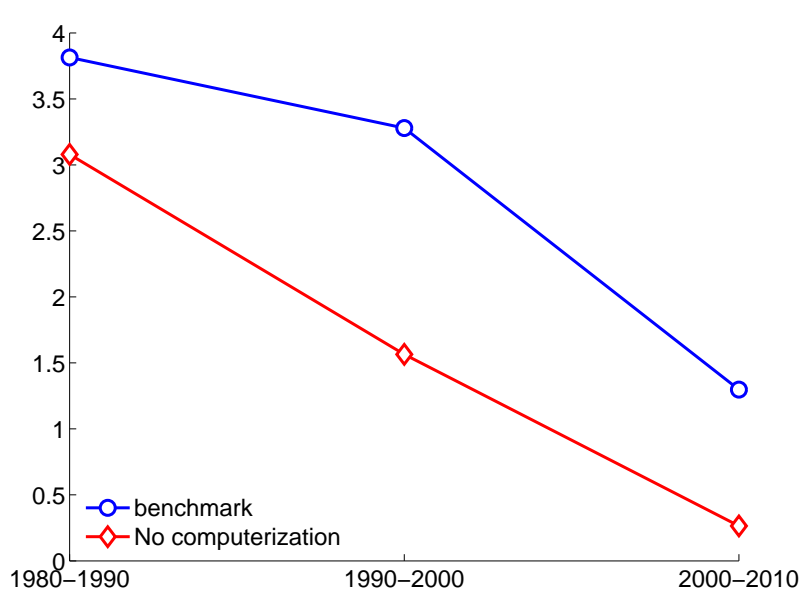

(b) Growth rate

Fig. 13: Aggregate output without computerization 


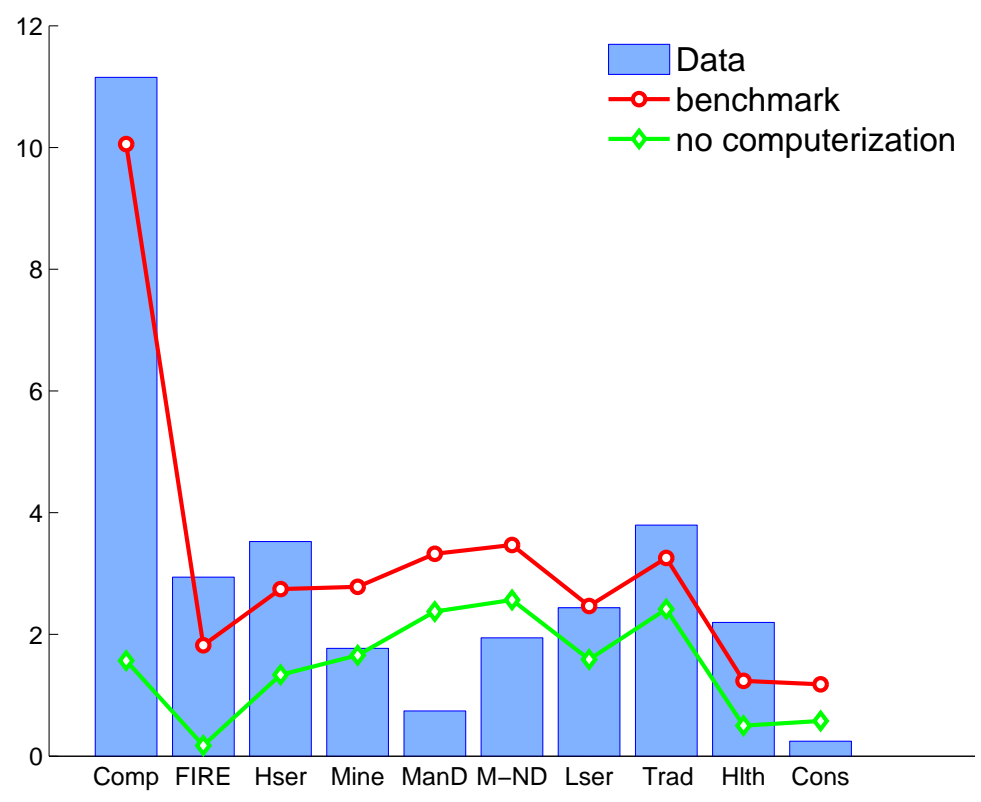

Fig. 14: Output growth by industry without computerization

In panel (a), we plug in model-simulated income shares and quantities into the accounting equations in (18). In panel (b), we plug in data from NIPA and FAT directly. See Table 1 for details of the industry classification. 


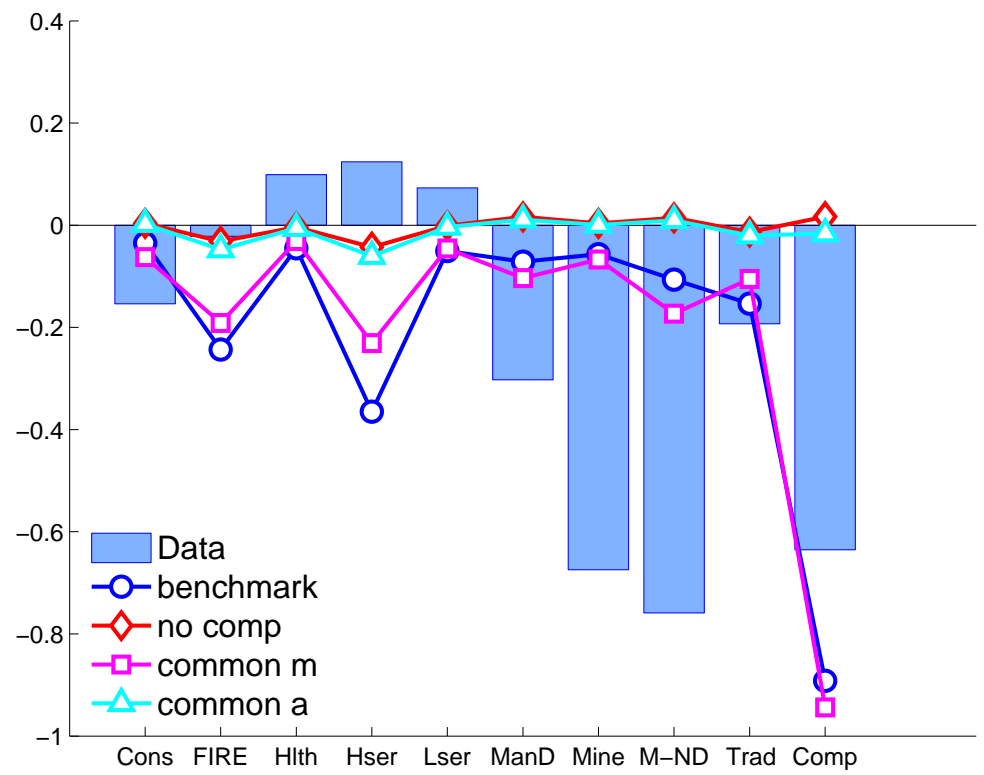

Fig. 15: Changes in labor income shares by industry

"no comp": no computerization. "common m": no complementarity across jobs. "common a": no complementarity across industries. See Table 1 for details of the industry classification. 


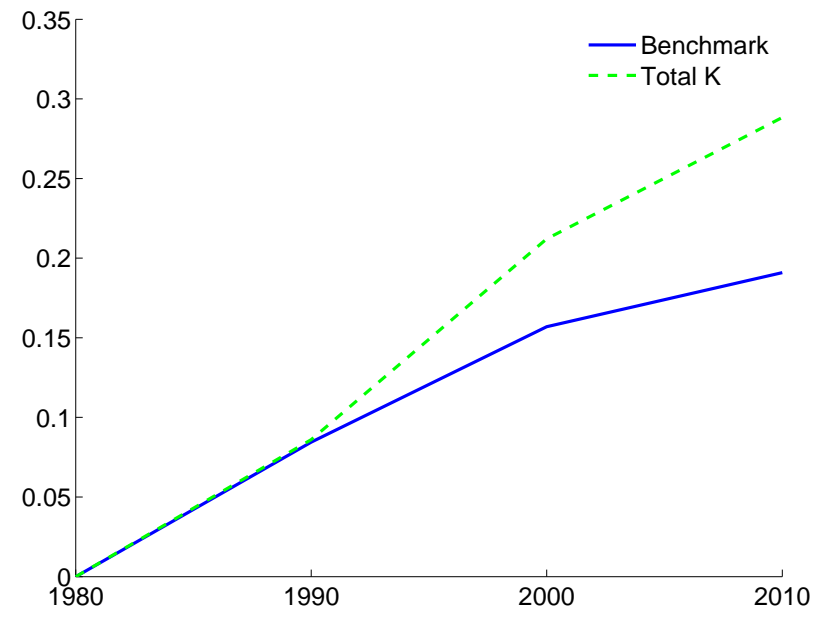

(a) Model

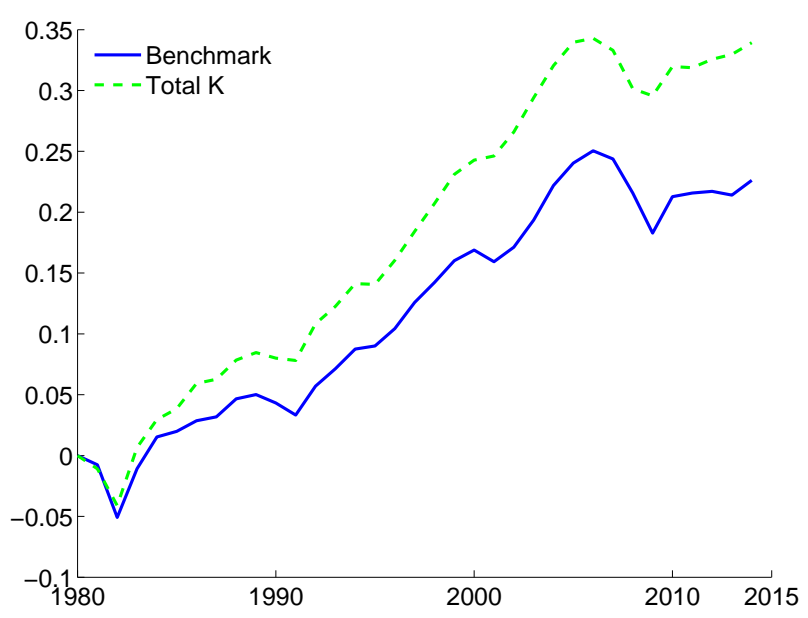

(b) Data

Fig. 16: Comparing different measures of TFP's

In panel (a), we plug in model-simulated income shares and quantities into the accounting equations in (18). In panel (b), we plug in data from NIPA and FAT directly. 


\section{Appendix: Additional Tables and Figures}

\begin{tabular}{l|llllllllll}
\hline & Const & FIRE & Health & $\begin{array}{l}\text { High } \\
\text { serv. }\end{array}$ & $\begin{array}{l}\text { Low } \\
\text { serv. }\end{array}$ & Dur & Mine & $\begin{array}{l}\text { Non- } \\
\text { durable }\end{array}$ & $\begin{array}{l}\text { Trade } \\
\text { uter }\end{array}$ \\
\hline$\sigma=.1$ & 1.577 & 1.260 & 1.497 & 1.579 & 1.447 & 1.222 & 1.423 & 1.462 & 1.505 & 1.828 \\
$\sigma=.5$ & 1.593 & 1.245 & 1.473 & 1.546 & 1.436 & 1.225 & 1.422 & 1.473 & 1.480 & 1.825 \\
$\sigma=.7$ & 1.624 & 1.229 & 1.444 & 1.506 & 1.423 & 1.234 & 1.426 & 1.498 & 1.451 & 1.825 \\
$\sigma=.815$ & 1.699 & 1.213 & 1.413 & 1.461 & 1.415 & 1.263 & 1.445 & 1.559 & 1.419 & 1.840 \\
\hline
\end{tabular}

Table 8: Calibrated $\rho_{i}$ 's across various $\sigma$ 's

For each value of $\sigma$, the $\rho_{i}$ 's are calibrated as explained in Section 4.1 except that $\sigma$ is fixed. We found that for values of $\sigma$ above its benchmark value of 0.815 , the model fit quickly becomes exponentially poor with no solution as it approaches 1 . The reason is that occupation-specific productivities $M_{j}$ become so large that it becomes impossible to simultaneously match employment share changes and measured TFP by industry.

\begin{tabular}{ccccc}
\hline & \multicolumn{2}{c}{ Output } & \multicolumn{2}{c}{ Productivity } \\
& Data & Model & Data & Model \\
\hline $\mathbf{1 9 8 0 -}$ & 3.41 & 3.81 & $0.43^{*}$ & 0.85 \\
$\mathbf{1 9 9 0 -}$ & 3.75 & 3.28 & 1.26 & 0.73 \\
$\mathbf{2 0 0 0 -}$ & $\mathbf{1 . 5 4}$ & $\mathbf{1 . 3 0}$ & $\mathbf{0 . 4 4}$ & $\mathbf{0 . 3 4}$ \\
\hline
\end{tabular}

Table 9: Model fit to aggregate output and productivity

Data source: BEA NIPA. *Although average productivity growth seems low in the data for the 1980s, this is more of a cyclical phenomena in the early 1980s that persisted from the late 1970s. For example, average productivity growth from 1982-1990 is $1.18 \%$. 


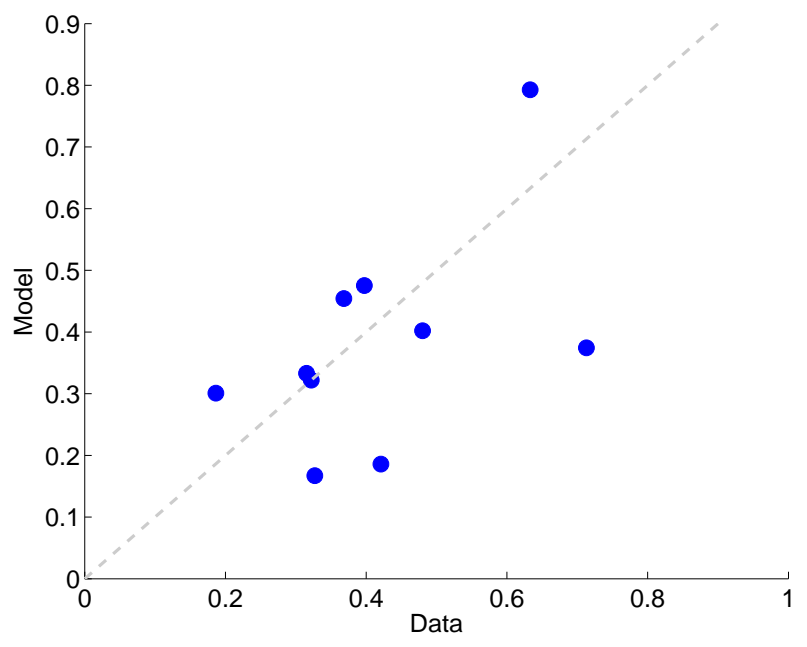

(a) Traditional Capital share

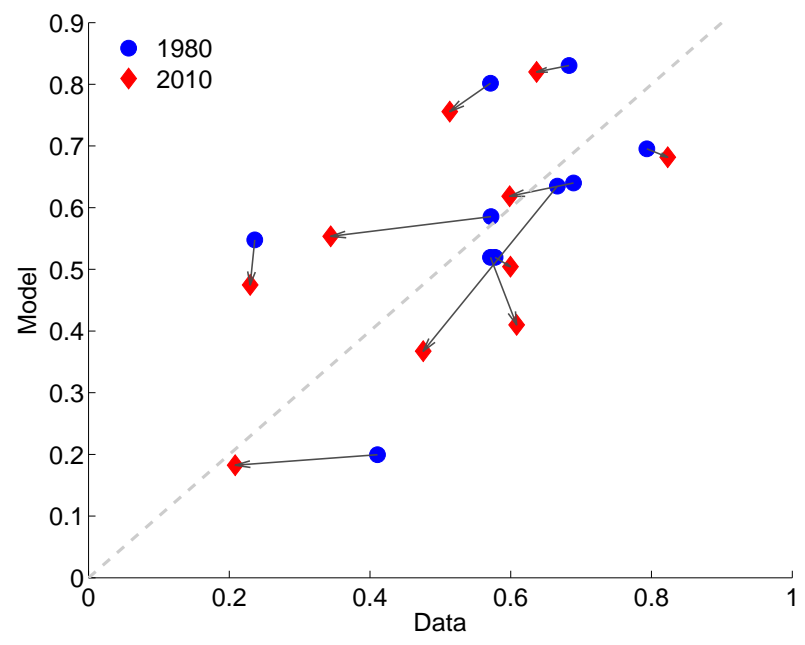

(b) Labor share

Fig. 17: Factor income shares by industry: model vs. data

In the model, traditional capital income shares are computed by first fixing that of the computer industry's to 1980 data as explained in Section 4.1, and then calibrating them for all other industries using a method of moments. Data traditional capital income shares are computed by applying the procedure in Section 4.1 too all industries in 1980. All data from BEA NIPA and FAT. 